\title{
Complex Effects of Drum Hub Forms and Structural Parameters on Coal Loading Performance
}

\author{
Kuidong Gao $\mathbb{D}^{1,2}$ Xiaodi Zhang $\mathbb{D}^{1,}{ }^{1}$ Liqing Sun, ${ }^{1}$ Qingliang Zeng $\mathbb{D}^{1,2}$ and Kao Jiang $\mathbb{D}^{1}$ \\ ${ }^{1}$ College of Mechanical \& Electrical Engineering, Shandong University of Science \& Technology, Qingdao 266590, China \\ ${ }^{2}$ Shandong Province Key Laboratory of Mine Mechanical Engineering, Shandong University of Science and Technology, \\ Qingdao 266590, China
}

Correspondence should be addressed to Kuidong Gao; gaokuidong22@163.com

Received 10 January 2020; Revised 15 May 2020; Accepted 21 May 2020; Published 10 June 2020

Academic Editor: Dan Selişteanu

Copyright (C) 2020 Kuidong Gao et al. This is an open access article distributed under the Creative Commons Attribution License, which permits unrestricted use, distribution, and reproduction in any medium, provided the original work is properly cited.

\begin{abstract}
The extremely poor loading performance of a thin coal shearer drum affects the mining efficiency in thin seam mining seriously on account of the restriction by the complicated mining environment and seam thickness. The coal loading performance of the drum is influenced by several complex factors, such as motion parameters and structural parameters, including the structure and form of the hub. The form of the drum hub is cylindrical in general, and in order to study the influence of the hub form on the coal loading rate of the drum, seven drums with different hub forms and structures were designed. The influence of the complexity of hub structures on the coal loading performance was studied by discrete element method (DEM) simulation in this paper. The change curves with the research object of different drums, such as coal loading rate, velocity field distribution, and contact force between fallen coal particles, were obtained. The results showed that the conical hub drum can improve the coal loading performance than the cylindrical hub drum, and the curve-shaped hub drum had a more obvious promotion on the coal loading performance. The coal loading rate increased first and then decreased with the increase of hub cone angle. Compared with the conical hub drum, the curve-shaped hub drum can not only improve the coal loading rate, but also has a larger space containing coal. This study has proposed a drum with a new form hub which could increase the coal loading rate, and the methods and conclusions provide the guidance for drum hub design.
\end{abstract}

\section{Introduction}

The shearer is the important device in longwall mining, whose performance affects the mining capacity and efficiency directly. As a main component of the shearer, the drum is mainly used for coal cutting and loading, whose performances are the key factors that influence the shearer performance. The cutting action of the drum has been studied by the scholars' abundant research studies $[1,2]$; Yang et al. [3] studied the wear in conical picks in rotationdrilling cutting progress by experimental and theoretical methods. Zhao et al. [4] used ANSYS/LS-DYNA software to study the dynamic transmission law of the spiral drum cutting coal rock and obtained the stress distribution of the drum in the cutting process. Liu et al. [5] proposed a new three-drum shearer and studied the cutting performance of the pick in deep coal conditions. Huang et al. [6] used the finite element method to simulate rock cutting process under confining pressure and obtained the influence of confining pressure on the cutting force. However, the research studies about loading action of the drum are still insufficient, and many research studies were conducted in the last century. The coal conveying performance of the drum is influenced by several factors which include vane, hub, wear-resistant plate, picks, and pick holder, and the influences are in complexity. As the complex mining conditions and environment are with smaller mining heights in the thin coal seam, the diameter of the drum and the depth of the vane are small, resulting in the complex coal loading procedure and poor loading performance which caused the lower mining efficiency and the increment of the labor input. Therefore, the study about the coal loading performance of 
the drum is extremely important and necessary. Through summarizing the research results of previous scholars on the shearer drum in the medium and thick coal seam, the influence of the drum structure and motion parameters on the coal loading performance of the drum was obtained by Brooker [7]. Ludlow and Jankowski [8] concluded that the wrap angle of vanes should be less than $360^{\circ}$, and the more vane number and material speed would reduce the drum loading rate. The factors which include the number of vanes, wrap angle of vanes, drum rotational speed, and hauling speed that affected the drum loading performance were pointed out by Peng [9] and Hurt and Mcstravick [10]. Based on the previous research studies, the loading performance of a new style drum called "Globoid drum" was investigated by Ayhan and Eyyuboglu [11], and they proved the higher loading performance of this drum. Liuet al. [12] studied the effects of factors such as the vane helix angle, drum rotational speed, and hauling speed on the coal loading rate of the drum and found the matching parameter with the best coal loading performance by using the coal-rock cutting testbed. In addition to the above research studies, Gao et al. [13] also studied the influence of working face conditions and structures of the ranging arm of the shearer on the drum coal loading rate by DEM simulation. Bołoz [14] designed a type of longwall shearer, which was applicable to mining thin hard coal seams, and this shearer operation technology and possible daily output achievement were introduced in his study in detail. In 2015, Wydro [15] researched the influences of filling rate and coal plate on the transport rate of the bulk coal with the help of a self-developed drum test bench for coal transport. In 2016, the coal loading process of a shearer was simulated by Gospodarczyk [16] using PFC3D, and the drum transport effect and coal particle movements under circumstances of cutting top coal, cutting bottom coal, and with and without the coal plate were studied.

In order to study the complex transportation process of bulk materials better, Cundall and Strack $[17,18]$ put forward the DEM for the first time. With the development of numerical simulation technology, the DEM has been widely used in the fields of bulk material transportation, material screening, rock cutting, rock crushing, pharmaceutical engineering, and fluidized bed [19-22]. Meanwhile, many scholars have also completed the design and performance analysis of complex mechanical structures, such as feeder [23], chain conveyor [24], and belt conveyor [25]. Potyondy and Cundall [26] proposed that the DEM can simulate the bulk properties of the real coal rock after crushing, and the crushed coal rock had the properties of the granular material, so the DEM can be applied to the analysis of the coal loading performance of the drum. Dai et al. [27] performed the uniaxial and triaxial numerical simulations of seafloor massive sulfides by leveraging the PFC3D code and predicted the maximum force on the cutting pick. Li et al. [28] studied the drum cutting properties through DEM simulations and concluded that the DEM is an easier, faster, and reasonable method in the prediction of drum cutting load and design of the shearer drum. Furthermore, Gao [29] combined the experimental research and the DEM simulation to study the influence of the helix angle of the blade on the coal loading performance and proved the accuracy and feasibility of the DEM in the simulation of coal conveying process of the drum.

Several scholars have conducted considerable research studies with experimental verification and DEM simulation on factors affecting the coal loading performance of the drum, including motion parameters (rotational speed and hauling speed) and structure parameters (the number and helix angle of blades and web depth) of the drum, but the research about the influence of the structure of the hub on the coal loading performance was not reported. Studying the coal conveying performance of the drum with the experimental method was high cost, and the macroscopic appearance could be observed merely, while the essence of influences in complexity at a microlevel could not be revealed. Therefore, this paper studied the coal loading rate, the three-direction velocity of coal particles, the number of particles in different web depths, and the contact force of particles under different structures of the drum hub by the DEM. In the results of this paper, the influence of the hub form and structures and the rotational speed of the drum on the coal loading rate and the coal particle conveying process was obtained, and the character of these complex influences was discussed and analyzed. This study provides a reference and guidance for the design of the drum hub and the working parameter selection of the shearer in the complex working environment such as thin coal seams.

\section{Methodology}

The DEM has been applied in different fields by many scholars worldwide to solve many complex engineering problems. According to the research content of this paper, the coal face is a cohesive body with continuous property before crushing, and then the broken coal can be regarded as a loose material with discrete property after crushing. The bonding model proposed by Potyondy and Cundall [26] can simulate the continuity of the coal before breaking, so the bonding model is selected as the model of building the coal face in the DEM. In order to describe the contact force and displacement between particles and the relative movement of particles, the linear contact model and the sliding model are selected in the DEM.

2.1. Linear Contact Model. The relationship between particles of normal contact force, shear contact force, and displacement in the linear contact model can be expressed as follows:

$$
\left\{\begin{array}{l}
F_{i}^{n}=K^{n} U^{n} n_{i}, \\
\Delta F_{i}^{s}=-K^{s} \Delta U_{i}^{s},
\end{array}\right.
$$

where $F_{i}^{n}$ is the normal contact force; $F_{i}^{s}$ is the shear contact force; $U^{n}$ is the tangential displacement increment; $U_{i}^{s}$ is the shear component of the contact displacement-increment vector; $K^{n}$ is the normal contact stiffness; $K^{s}$ is the shear contact stiffness; $n_{i}$ is the unit normal vector of particles; and $i$ is the number of particles. 
The normal contact stiffness can be expressed as follows:

$$
K^{n}=\frac{k_{n}^{[A]} k_{n}^{[B]}}{k_{n}^{[A]}+k_{n}^{[B]}},
$$

where $k_{n}^{[A]}$ and $k_{n}^{[B]}$ are the normal stiffness of two contact particles.

The shear contact stiffness can be expressed as follows:

$$
K^{s}=\frac{k_{s}^{[A]} k_{s}^{[B]}}{k_{s}^{[A]}+k_{s}^{[B]}},
$$

where $k_{s}^{[A]}$ and $k_{s}^{[B]}$ are the normal stiffness of two contact particles.

2.2. Slip Model. The slip is enforced by verifying whether the maximum static friction force is exceeded by the shearing force. The maximum static friction force is calculated using the minimum friction coefficient $\mu$, and this friction force can be expressed as follows:

$$
F_{\text {max }}^{s}=\mu\left|F_{i}^{n}\right| .
$$

The slip will occur between the two contact particles when the shear contact force $F_{i}^{s}$ meets $\left|F_{i}^{s}\right|>F_{\max }^{s}$ in equation (4).

2.3. Bonding Model. The bonding model is mainly used to determine the contact between two particles before the coal face is broken. Since this paper mainly studied the cutoff coal particle conveying performance of the drum, the normal and the tangential bonding strength between the particles only need to ensure that the coal face can maintain a static structure during the cutting process. When the force exerted on the particles in the normal and tangential direction exceeds the tensile or tangential bond strength, the bond between particles breaks, and the particles are cut off. The constitutive behavior for contact occurring at a point is indicated in Figure 1.

The fatigue failure criterion of two bonding models can be expressed as follows:

$$
\left\{\begin{array}{l}
F_{n}^{c} \geq R_{n} \\
F_{s}^{c} \geq R_{s}
\end{array}\right.
$$

where $R_{n}$ and $R_{s}$ are the normal and the tangential bonding strength of the particles, respectively.

\section{Simulation Model Establishment}

In an ideal coal mining process, the coal cutoff from the coal face could be loaded by the drum onto the middle chute of the conveyor and transported out of the working face. However, some of the fallen coal were thrown to the goaf and became the floating coal. In addition, some other fallen coal piled up in the area between the coal face and the chain conveyor due to the insufficient axial velocity and led to a negative impact on the move of the conveyor towards the coal face. Based on the above problems, the effect of the drum on particle ejection speed and axial velocity has an important impact on the coal loading performance. In addition to the influence of the motion parameters and the structure parameters of the vane, the structure parameters of the hub also play an important role in affecting the motion behavior of particles. Therefore, four drums with the conical hub were designed on the basis of the cylinder hub drum, as shown in Figure 2 (I), (II), (III), (IV), and (V), where $\Psi$ is the cone angle of the hub, but the conical hub leads to a lower drum space capacity to a certain extent, so three drums with the curve-shaped hub were designed, as shown in Figure 2 (VI), (VII), and (VIII), where $K_{i}$ is the average curvature of the hub. The curve-shaped hub drums not only increased the axial velocity of coal particles but also provided the bigger drum space capacity, and the parameters of the drum hub are shown in Table 1. As one of the motion parameters of the drum, the rotational speed has important and complex impacts on the loading performance of the drum. Therefore, this paper studied the coal loading performance of the drum combined with the effects of structures of the drum hub and the rotational speed, and the optimal matching relationship between the rotational speed and hub structures was obtained.

The equipment on the underground coal mining working face and the numerical simulation model are illustrated in Figure 3(a). The equipment of the coal mining working face is mainly composed of a shearer, a hydraulic support, and a chain conveyor, for coal cutting and loading, supporting the roof, and transportation, respectively. As the main research object, the drum model was established in simulation. Additionally, it has been proved that the ranging arm of the shearer and the relative position relationship between the chain conveyor and the drum have a significant effect on the coal loading rate $[13,30]$, so the ranging arm and the chain conveyor model were also established in simulation. In order to reduce simulation time and simplify the model, the hydraulic support which would not affect the simulation result was not established. In the working process of the drum, its rotation direction includes from the roof towards the floor and from the floor towards the roof, corresponding to two coal loading methods of drum pushing and drum ejection, as shown in Figure 3(b). Figure 4 shows the comparison of the coal loading rate of different drums with drum pushing and ejection and the results of the coal loading rate of drum (I) with drum pushing and ejection under different rotational speeds. It can be seen that the coal loading rate with the drum ejection method was better than that of the drum pushing method, obviously. In the process of mining thin coal seam, the coal cutting and loading mainly depend on the front drum. Therefore, this paper only focused on the coal loading performance with the drum ejection method.

The particle and material parameters in the simulation are shown in Table 2. The parameters of the drum structures web depth, diameter of the loading vane, helix angle, and the diameter of the hub were $650 \mathrm{~mm}, 800 \mathrm{~mm}, 23^{\circ}$, and $400 \mathrm{~mm}$, respectively. In order to study the loaded coal particles with different web depths, the coal face particles were dyed according to web depth, in which the width of green, red, blue, and yellow particles was $150 \mathrm{~mm}$, and the width of orange particles was $50 \mathrm{~mm}$. In the simulation 

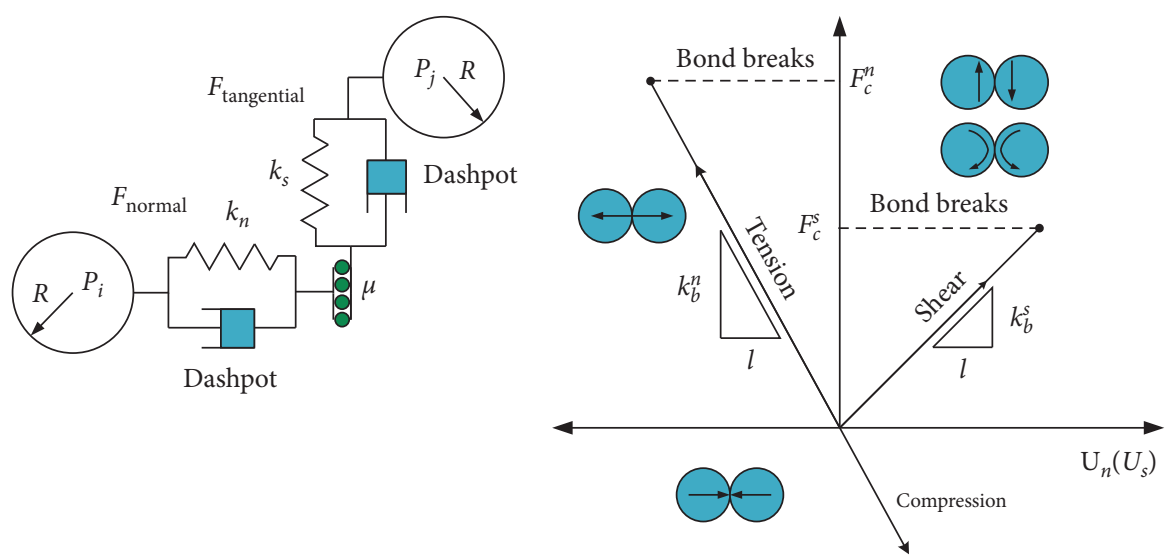

(a)

(b)

FIGURE 1: (a) The particle contact model in the DEM; (b) constitutive behavior in the contact bonding model.
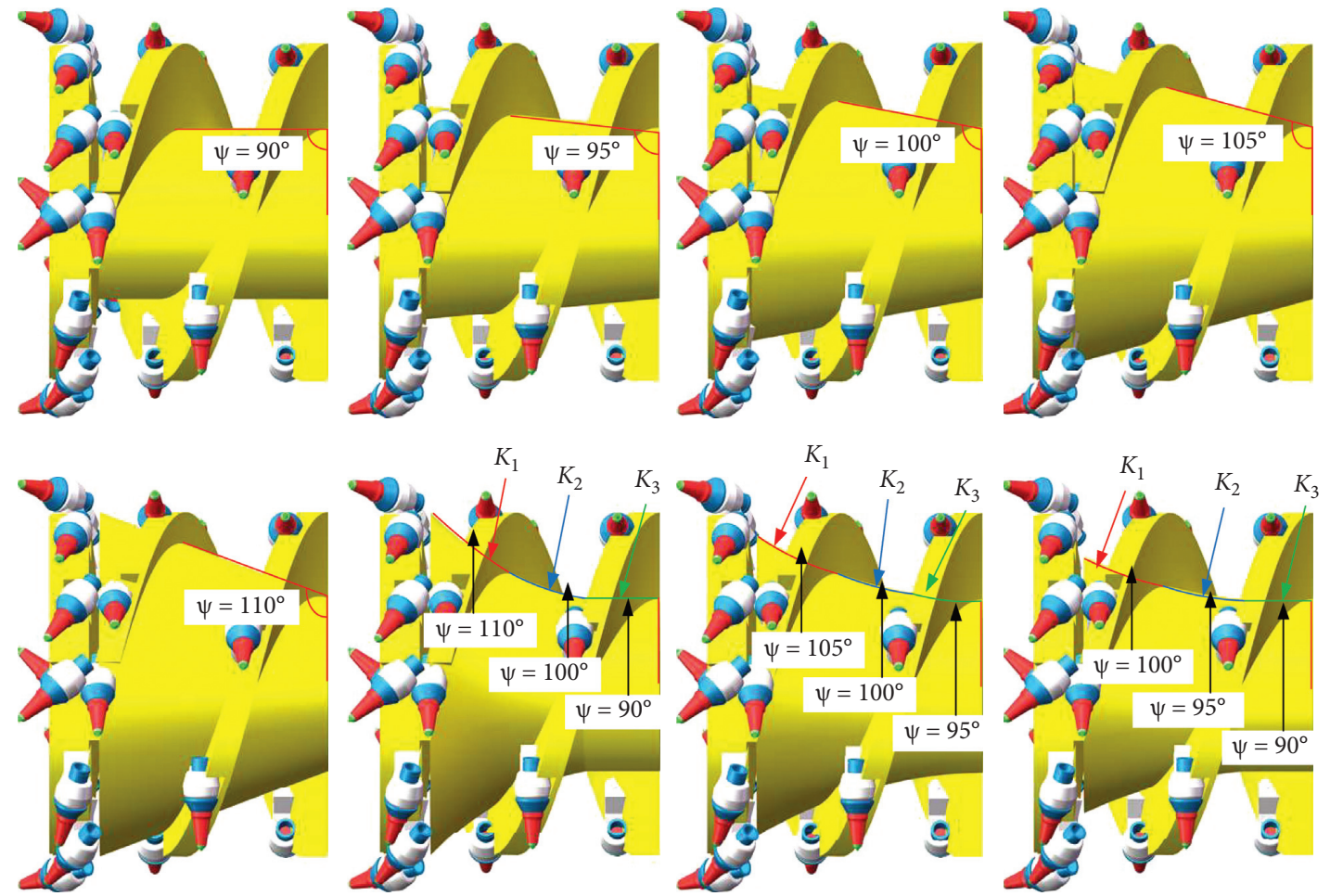

FIgURE 2: The drums with different forms and structures of the hub.

TABle 1: The structure parameters of the drum hub.

\begin{tabular}{lllcccccc}
\hline Drum & I & II & III & IV & V & VI & VII \\
\hline & & & & & & $K_{1}=1.638 e-1 ;$ & $K_{1}=1.224 e-1 ;$ & $K_{1}=1.017 e-1 ;$ \\
$\Psi\left({ }^{\circ}\right) / K_{i}$ & 90 & \multirow{2}{*}{95} & \multirow{2}{*}{100} & \multirow{2}{*}{105} & \multirow{2}{*}{110} & $K_{2}=1.001 e-1 ;$ & $K_{2}=7.984 e-2 ;$ & $K_{2}=5.401 e-2 ;$ \\
& & & & & & $K_{3}=0$ & $K_{3}=0$ \\
\hline
\end{tabular}

process, the coal falling area was divided into three parts. The goaf was area I, the area between the middle chute of the chain conveyor and the coal face was area II, and the middle chute of the chain conveyor was area III, which is the statistical area of loaded particles. The coal loading rate was the ratio of the loaded coal particle mass in area III and the total fallen coal particle mass, as shown in Figure 5. Due to the interaction between the drum and the coal particles in the coal loading process, the movement of the coal particles showed randomness and complexity. In order to reveal the coal loading mechanism and the drum-particle interaction mechanism of drums with different hubs, the number and 


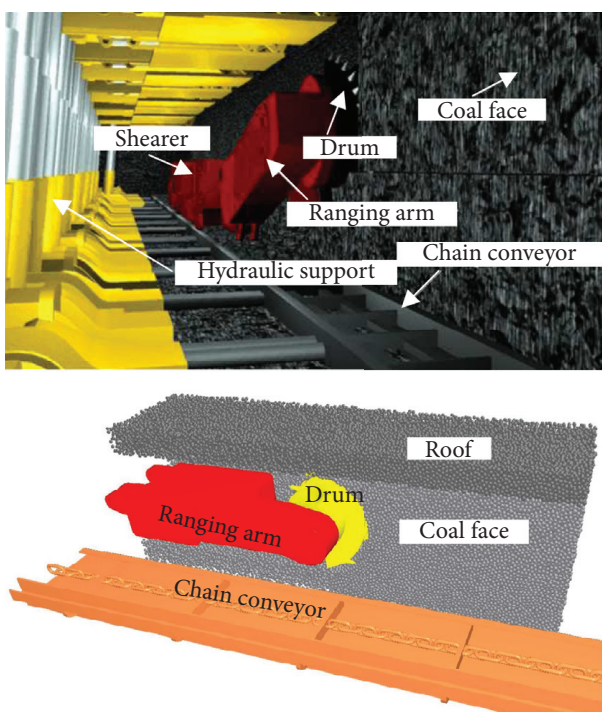

(a)

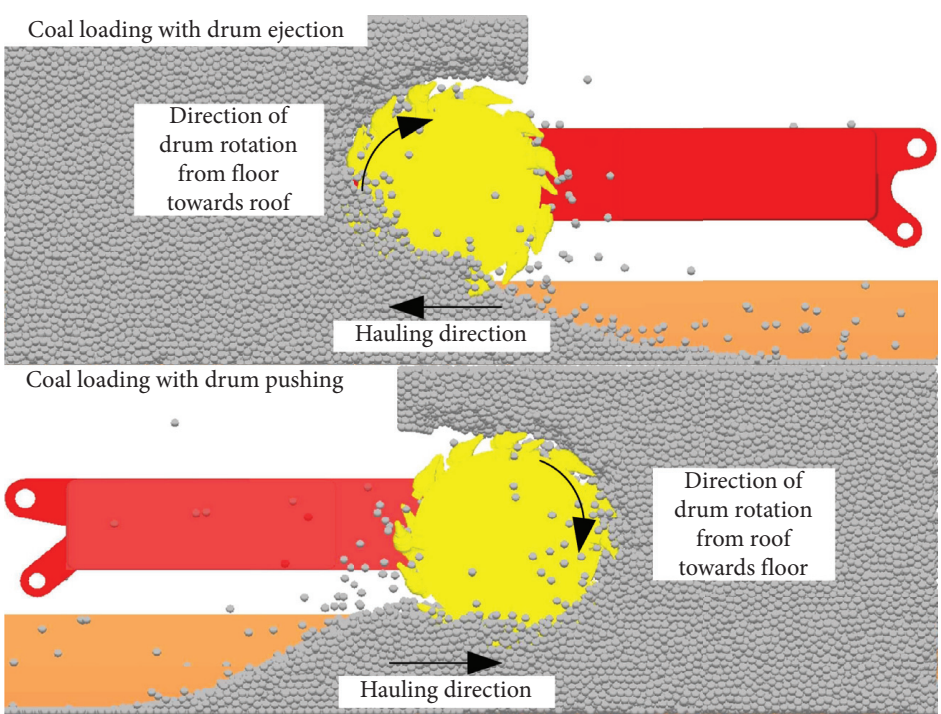

(b)

Figure 3: (a) Shearer in operation; (b) the coal loading process of the drum in simulation.

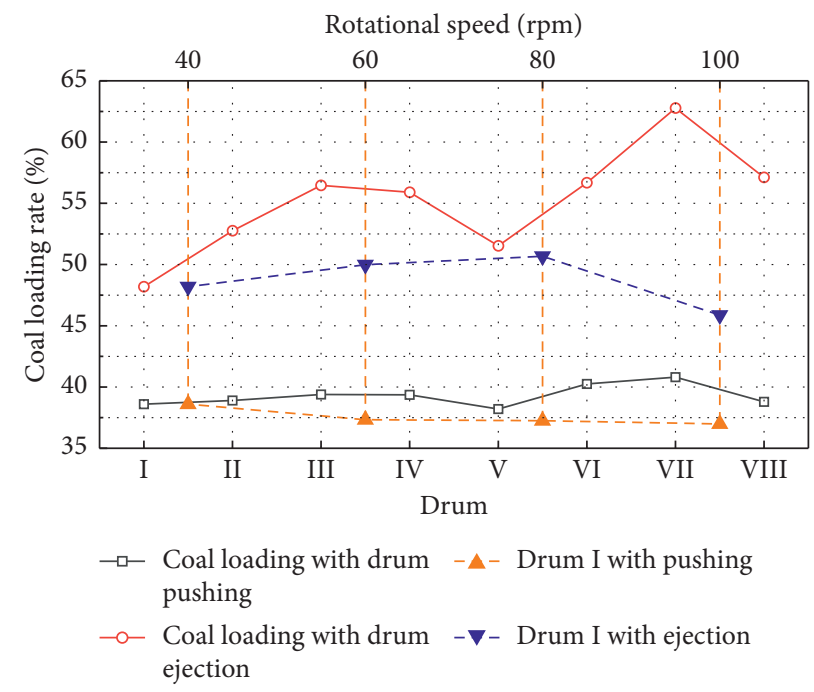

FIGURE 4: The comparison of different coal loading methods.

TABLE 2: The parameters of the particle in the simulation.

\begin{tabular}{lccc}
\hline & Density $\left(\mathrm{kg} / \mathrm{m}^{3}\right)$ & Poisson's ratio & Young's modulus $(\mathrm{GPa})$ \\
\hline Coal & 1400 & 0.28 & 4.25 \\
Steel & 7800 & 0.30 & 206 \\
\hline & Coefficient of restitution & Coefficient of static friction & Coefficient of rolling friction \\
Coal-coal & 0.50 & 0.80 & 0.10 \\
Coal-steel & 0.50 & 0.60 & 0.05 \\
\hline
\end{tabular}

velocity of particles at different positions inside the drum were counted. Hence, based on each cut line of the pick on the vane, the envelop zone of the loading vane was used as the statistical zone, and the width of the hub was divided into five equal zones as shown in Figure 6, so as to ensure that each statistical zone had the same amount of particles cut from the coal face in unit time. Furthermore, the right half of the drum and the coal face formed a closed area, while the left half was an open area, and the vanes mainly interact with the particles in the right half of the drum. In order to study the contact force and the conveying performance of particles inside the drum, the right half of the drum was divided into two equal statistical areas, as shown in Figure 6. 


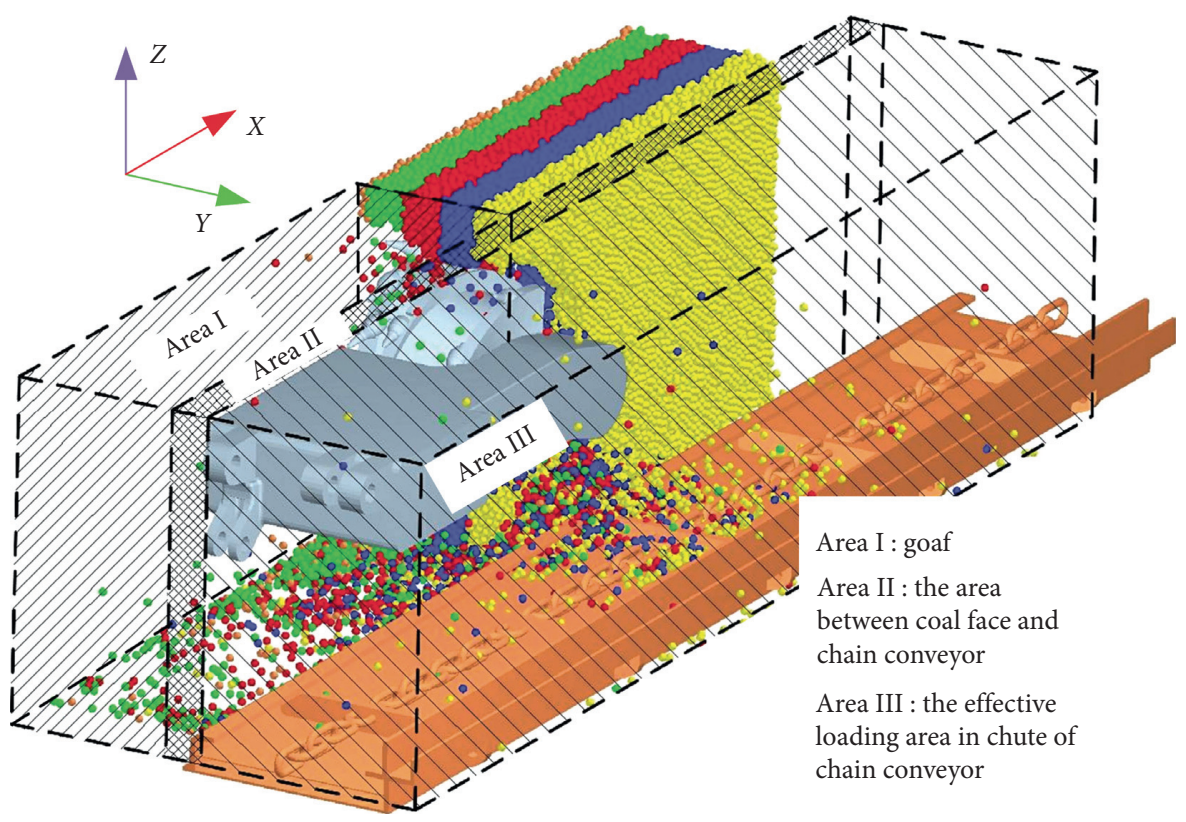

FIGURE 5: Statistical area division of coal loading.

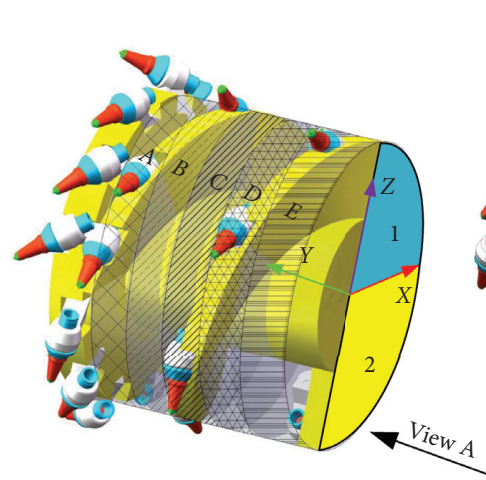

(a)

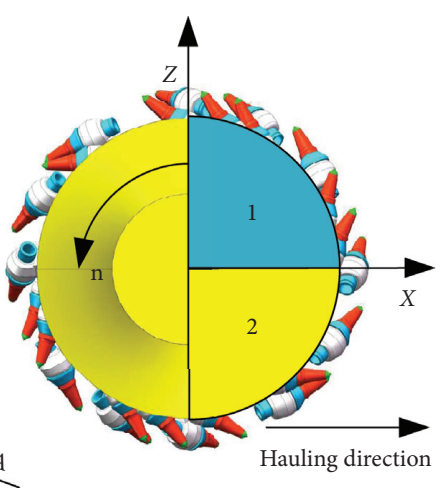

View A

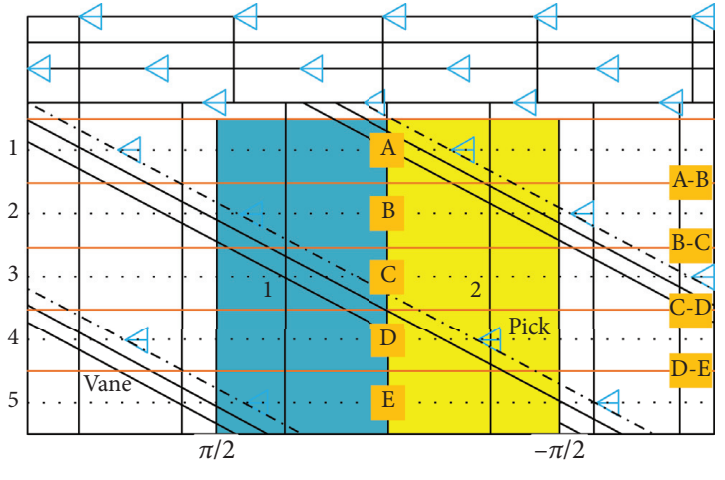

Expanded view

(b)

Figure 6: The statistical zone of the drum with different web depths. (a) View A. (b) Expanded view.

\section{Analysis of the Simulation Results and Discussion}

4.1. The Influence of the Rotational Speed and the Hub Structure on Coal Particle Velocities in Three Directions. In the simulation process, the hauling speed of the drum was set to $4 \mathrm{~m} / \mathrm{min}$, and the rotational speed was $40 \mathrm{rpm}, 60 \mathrm{rpm}$, $80 \mathrm{rpm}$, and $100 \mathrm{rpm}$, respectively. The velocities of particles influenced by the combination of drum hub structures and rotational speed were studied. Figure 7 demonstrates the variation curves of the coal loading rate of eight drums with rotational speed. For different matching of the hub structures and drum rotational speed, the relationship between the particle velocities and the coal loading rate has been shown in Table 3 and Figure 8.

As indicated in Figure 7, with the increase of the value of $\Psi$, the rotational speed required for the drum to obtain the best coal loading performance decreases. In the case of the same rotational speed, the particle velocity under different drums in $X$ and $Z$ directions was not different, significantly, while that in the $Y$ direction, namely, the axial direction, was significantly different, as shown in Figure 8 and Table 3. The axial velocity of particles increased with the increase of the value of $\Psi$, and the lower the rotational speed, the more obvious the difference. When the rotational speed increased from $40 \mathrm{rpm}$ to $100 \mathrm{rpm}$, the velocity difference in the $Y$ direction between drums (V) and (I) decreased from four times higher to two times. The reason for that was when the rotational speed was small, the packing density of particles inside the drum was large, and the hub had an obvious impact on the particles. With the increase of the rotational speed, the packing density of particles inside the drum decreases, which leads to the decrease of contact between the hub and particles, and the vanes gradually played a leading role, resulting in the reduction of the velocity difference. In the case of the same 


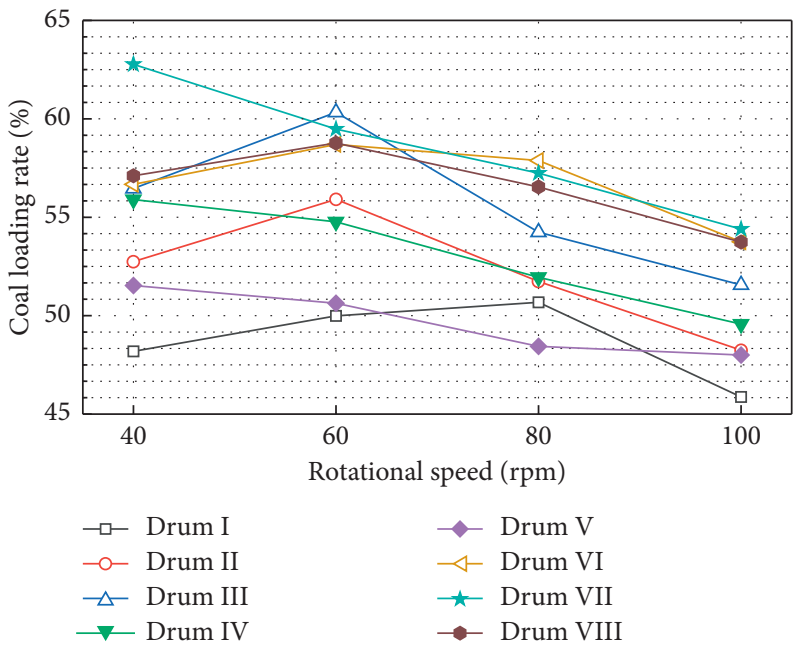

Figure 7: The coal loading rate curve of eight drums at different rotational speeds.

TABLE 3: The statistical analysis of particle velocities in three directions and coal loading rate.

\begin{tabular}{|c|c|c|c|c|c|}
\hline$n(\mathrm{rpm})$ & Drum & $X$ direction $(\mathrm{m} / \mathrm{s})$ & $Y$ direction $(\mathrm{m} / \mathrm{s})$ & $Z$ direction $(\mathrm{m} / \mathrm{s})$ & Loading rate (\%) \\
\hline \multirow{8}{*}{40} & I & 0.185 & 0.126 & 0.198 & 48.19 \\
\hline & II & 0.243 & 0.209 & 0.217 & 52.75 \\
\hline & III & 0.239 & 0.332 & 0.230 & 56.46 \\
\hline & IV & 0.219 & 0.371 & 0.244 & 55.90 \\
\hline & $\mathrm{V}$ & 0.241 & 0.459 & 0.238 & 51.53 \\
\hline & VI & 0.288 & 0.464 & 0.266 & 56.67 \\
\hline & VII & 0.265 & 0.368 & 0.333 & 62.77 \\
\hline & VIII & 0.245 & 0.238 & 0.229 & 57.11 \\
\hline \multirow{8}{*}{60} & I & 0.276 & 0.200 & 0.211 & 49.99 \\
\hline & II & 0.279 & 0.286 & 0.262 & 55.91 \\
\hline & III & 0.281 & 0.391 & 0.250 & 60.33 \\
\hline & IV & 0.267 & 0.469 & 0.139 & 54.77 \\
\hline & $\mathrm{V}$ & 0.261 & 0.538 & 0.254 & 50.63 \\
\hline & VI & 0.337 & 0.554 & 0.290 & 58.70 \\
\hline & VII & 0.333 & 0.462 & 0.317 & 59.48 \\
\hline & VIII & 0.261 & 0.319 & 0.234 & 58.77 \\
\hline \multirow{8}{*}{80} & I & 0.437 & 0.308 & 0.245 & 50.68 \\
\hline & II & 0.402 & 0.393 & 0.237 & 51.74 \\
\hline & III & 0.461 & 0.511 & 0.283 & 54.24 \\
\hline & IV & 0.424 & 0.572 & 0.221 & 51.95 \\
\hline & $\mathrm{V}$ & 0.429 & 0.680 & 0.211 & 48.44 \\
\hline & VI & 0.544 & 0.673 & 0.230 & 57.88 \\
\hline & VII & 0.547 & 0.573 & 0.284 & 57.24 \\
\hline & VIII & 0.483 & 0.380 & 0.219 & 56.54 \\
\hline \multirow{8}{*}{100} & I & 0.531 & 0.344 & 0.144 & 45.87 \\
\hline & II & 0.546 & 0.430 & 0.190 & 48.25 \\
\hline & III & 0.573 & 0.554 & 0.133 & 51.56 \\
\hline & IV & 0.577 & 0.621 & 0.138 & 49.57 \\
\hline & V & 0.673 & 0.746 & 0.143 & 48.00 \\
\hline & VI & 0.691 & 0.722 & 0.128 & 53.75 \\
\hline & VII & 0.596 & 0.591 & 0.162 & 54.40 \\
\hline & VIII & 0.487 & 0.427 & 0.148 & 53.74 \\
\hline
\end{tabular}

drum, the particle velocity in directions $Y$ and $Z$ increased with the increase of the rotational speed, while the velocity in the $X$ direction decreased. This is because with the increase of the rotational speed, the action of the vanes was more obvious, and the number and amplitude of the thrown particles increased, correspondingly, which led to the increase of the particle velocity in $Y$ and $Z$ directions to an extent. Due to the influence of the vanes, more particles were thrown from the right half of the drum to the left half, and the movement direction was reversed in the $X$ direction, resulting in a decrease in the velocity in the $X$ direction to some extent. 


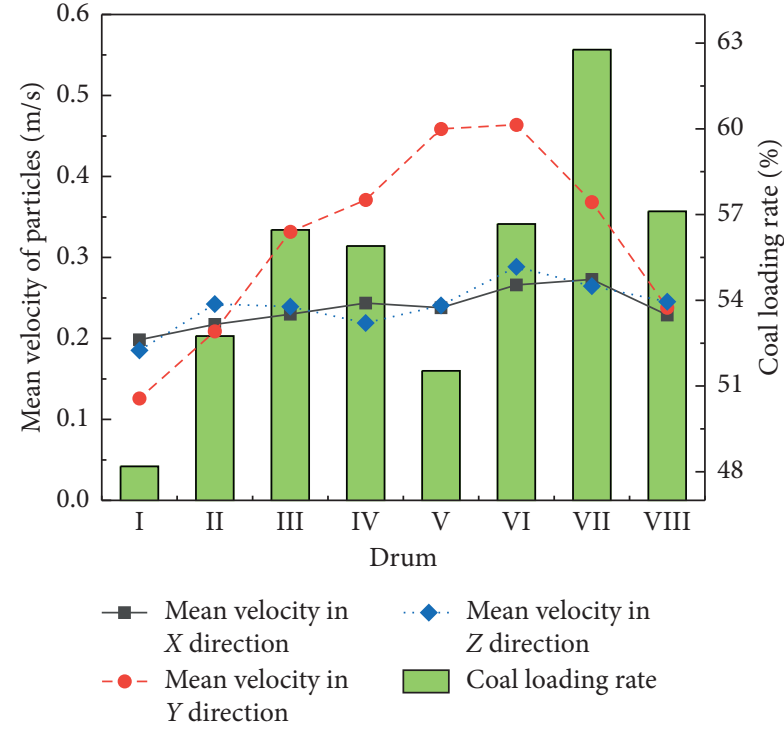

(a)

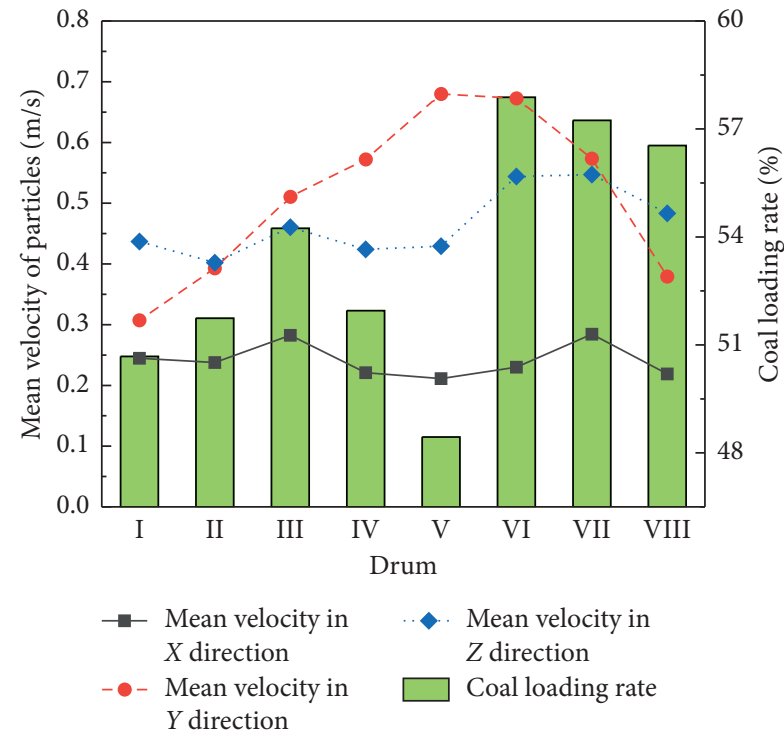

(c)

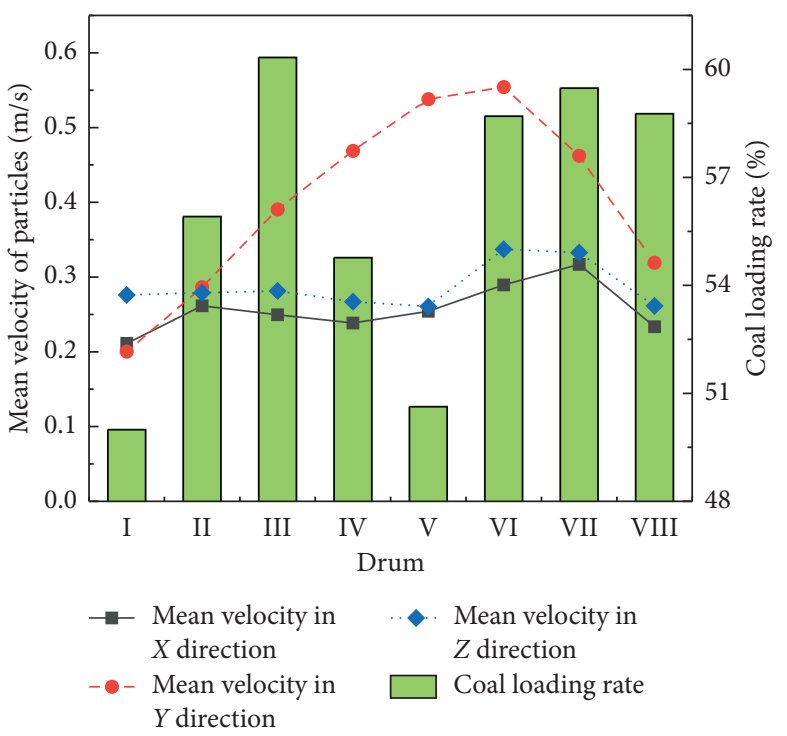

(b)

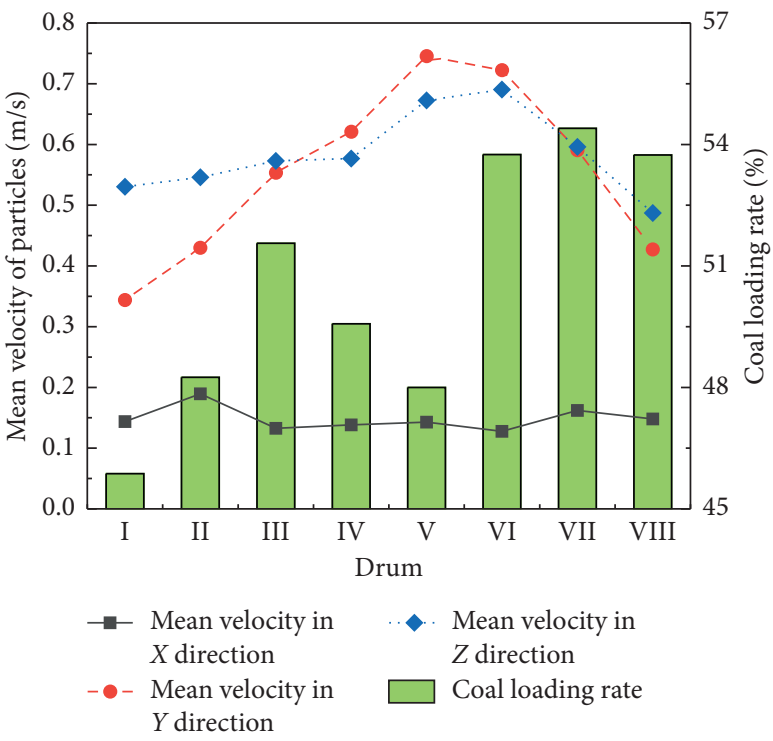

(d)

FIGURE 8: The relationship between particle velocity in three directions and loading rate at different rotational speeds: (a) $40 \mathrm{rpm}$, (b) $60 \mathrm{rpm}$, (c) $80 \mathrm{rpm}$, and (d) $100 \mathrm{rpm}$.

The coal loading performance of the drum depends on the axial velocity of particles to a large extent. Through the analysis of Table 3 and Figure 8, the axial velocity of particles and the coal loading rate of the drum increase with the increase in the value of $\Psi$, but when $\Psi>100^{\circ}$, with the increase in the value of $\Psi$, the axial velocity of particles still increases, while the coal loading rate decreases. The reason for that is the average diameter of the hub was too large due to the excessive cone angle, and the particles in the drum were compressed by the hub and fell into area II in the form of extrusion. Additionally, the axial velocity of particles in drums (VI), (VII), and (VIII) was close to that of drums (V), (IV), and (II), respectively. However, the diameter of the curve-shaped hub is smaller than that of the conical hub, so the squeezing effect of the particles by the hub was smaller, which led to a higher coal loading rate.

4.2. The Influence of the Drum Space Capacity on the Coal Conveying Performance. The drum space capacity depends on the diameter of the vane and the hub. The cone angle of the hub has a negative impact on the drum space capacity, especially in the case of the lower rotational speed, and the coal cutting rate of the drum is bigger than the conveying flow rate, which is prone to clogging. The theoretical conveying flow of the drum depends on the axial velocity of particles and the swept area by vanes, which is expressed by equation (6). The cutting rate of the drum is determined by 
the diameter, hauling speed, and web depth of the drum, which represents the volume of the coal excavated in unit time and is expressed by equation (7). The theoretical axial velocity of particles, cutting rate of the drum, and drum space capacity were studied by Gao et al. [31] in detail.

$$
Q_{z}=Q_{v} \cdot V_{p} \text {, }
$$

where $Q_{z}$ is the conveying flow rate of the drum; $Q_{v}$ is the swept area by the loading vane; and $V_{p}$ is the axial velocity of coal particles.

$$
Q_{t}=2 J \cdot R_{c} \cdot V_{q} \cdot \Psi_{v},
$$

where $Q_{t}$ is the cutting rate of the drum; $J$ is the web depth; $R_{c}$ is the radius of the drum; $V_{q}$ is the hauling speed of the drum; and $\psi_{v}$ is the loose coefficient of the coal.

In the simulation, the volume of excavated particles does not change after being cut off from the coal face, so the loose coefficient in the simulation was not taken into account. Additionally, there will be voids between particles in the coal face during the stacking process, so equation (7) was amended to the following equation:

$$
Q_{t}=2 J \cdot R_{c} \cdot V_{q} \cdot\left(1-\Psi_{q}\right),
$$

where $\psi_{q}$ is the porosity of the particles.

Table 4 and Figure 9 show the difference between the drum conveying flow rate and cutting rate at different drum rotational speeds.

In the case of different rotational speeds, the relationship between the conveying flow rate of the drum and the coal loading rate is shown in Figure 9. In can be seen that, from Figure 9(a), the smaller the difference between conveying flow rate and coal cutting rate is, the higher loading rate of the drum is; this is because the filling rate of particles in the enveloping zone of vanes was large, and the action of the vanes and the hub on the particles was obvious, which caused an increase in the coal loading rate. When the coal conveying flow rate of the drum was far bigger than the cutting rate, as drums (I) and (II), the filling rate of particles was too small, and effect of vanes and the hub on particles was weak. Moreover, as the value of $\Psi$ is increased, the average diameter of the hub increases, which caused the smaller depth of vanes and smaller drum space capacity, which increase the probability of particles accumulated in the left half of the drum and being thrown into the goaf, as shown in Figure 10.

As the rotational speed increases, in Figure 9, from 9(b) to $9(\mathrm{~d})$, it can be seen that although the conveying flow difference was the smallest, the coal loading rate was not the highest, which proved that, with the increase in rotation, the influence degree of the drum space capacity on the coal loading performance gradually decreased.

Figure 11 shows the contact forces between particles in different zones. As the rotational speed increases, the drum conveying performance increases, the packing density of particles in the drum was small, and the contact between particles was not intimate, so the contact forces in the statistical area decreased. By analyzing the difference in contact force between areas 1 and 2, it can be seen that the contact force in area 2 was significantly greater than that in area 1 at a lower rotational speed. As the rotational speed increases, the difference in contact force decreases; when the rotational speed reached $100 \mathrm{rpm}$, the particle contact force in area 1 was slightly bigger than that in area 2 . The main reason for that is when the rotational speed was low, the particles obtained a smaller ejection velocity. With the help of the gravity, a large amount of particles accumulated in area 2, and the number of particles in area 1 was less, resulting in the contact force far less than that in area 2. More particles were thrown to area 1 with the increase of the rotational speed, which led to the decrease of contact force. When the rotational speed reached $100 \mathrm{rpm}$, the particle contact in area 1 would be more than that in area 2 , so the contact force was slightly greater than that in area 2 . It can be seen from Figure 11 that, from statistical zone A to E, the contact force increased first and then decreased and reached the maximum value in zone $\mathrm{C}$. Because under the action of vanes, the particles were conveyed to the chain conveyor from the larger web depth, more particles were piled up in zone $\mathrm{C}$, which led to the increase in contact force, and zone $\mathrm{D}$ and $\mathrm{E}$ were close to the chain conveyor, where the particles were relatively scattered, so the contact forces were small. Meanwhile, with the increase of rotational speed, the fluctuation range of particle contact force decreases. In comparison with Table 4 and Figure 11, the particle contact force was negatively related to the drum space capacity. When the conveying flow rate was less than the coal cutting rate of the drum, the particle contact force was a peak value. Therefore, from the perspective of the drum space capacity, the value of $\Psi$ should be in a reasonable range.

\subsection{The Effect of the Drum Rotational Speed and Structures of} the Drum Hub on the Number of Coal Particles in the Drum. Figure 12 shows the cumulative mass of particles, passing through statistical zones $\mathrm{A}, \mathrm{B}, \mathrm{C}, \mathrm{D}$, and $\mathrm{E}$ in areas 1 and 2, respectively, according to different web depths. It can be seen from the figure that the particles move axially towards the chain conveyor under the action of vanes and sequentially pass through statistical zones $\mathrm{A}, \mathrm{B}, \mathrm{C}, \mathrm{D}$, and $\mathrm{E}$, so the cumulative mass of the particles increases gradually from $\mathrm{A}$ to $\mathrm{E}$.

Figure 12 indicates that the cumulative mass growth rate of particles in the drum decreases as the rotational speed increases, and the mass of particles left in area $\mathrm{E}$ at $40 \mathrm{rpm}$ was about twice that at $100 \mathrm{rpm}$, which proved that low rotational speed was favorable for particles to remain in the drum and reduced the probability of particles becoming floating coal. Meanwhile, the particle cumulative mass in the conical hub drum was obviously smaller than that in the cylinder hub drum as the cone angle of the hub had an adverse effect on the drum space capacity. Compared with Table 3 and Figure 12, the larger the cumulative mass of particles in both zone 1 and area $\mathrm{E}$ was, the higher the loading rate was. The reason for that was the altitude of zone 1 was greater than that of area 2, and the particles in zone 1 were easier to complete the effective loading with ejection. As the particles in area 2 were squeezed by the hub, they were inclined to fall into statistical area II. 
TABLE 4: The difference between conveying flow rate and cutting rate of drums with different rotational speeds.

\begin{tabular}{|c|c|c|c|c|c|c|c|c|c|}
\hline \multirow{2}{*}{$n(\mathrm{rpm})$} & \multirow{2}{*}{$\begin{array}{c}Q_{t}\left(\mathrm{~m}^{3} / \mathrm{min}\right) \\
\text { Drum }\end{array}$} & \multicolumn{8}{|c|}{1.371} \\
\hline & & I & II & III & IV & $\mathrm{V}$ & VI & VII & VIII \\
\hline \multirow{2}{*}{40} & $Q_{z}\left(\mathrm{~m}^{3} / \mathrm{min}\right)$ & 1.911 & 1.675 & 1.402 & 1.085 & 0.715 & 1.319 & 1.368 & 1.652 \\
\hline & $Q_{z}-Q_{t}\left(\mathrm{~m}^{3} / \mathrm{min}\right)$ & 0.540 & 0.304 & 0.031 & -0.286 & -0.656 & -0.052 & -0.003 & 0.281 \\
\hline \multirow{2}{*}{60} & $Q_{z}\left(\mathrm{~m}^{3} / \mathrm{min}\right)$ & 2.867 & 2.513 & 2.103 & 1.628 & 1.073 & 1.979 & 2.052 & 2.478 \\
\hline & $Q_{z}-Q_{t}\left(\mathrm{~m}^{3} / \mathrm{min}\right)$ & 1.496 & 1.142 & 0.732 & 0.257 & -0.298 & 0.608 & 0.681 & 1.107 \\
\hline \multirow{2}{*}{80} & $Q_{z}\left(\mathrm{~m}^{3} / \mathrm{min}\right)$ & 3.822 & 3.350 & 2.804 & 2.170 & 1.430 & 2.638 & 2.736 & 3.304 \\
\hline & $Q_{z}-Q_{t}\left(\mathrm{~m}^{3} / \mathrm{min}\right)$ & 2.451 & 1.979 & 1.433 & 0.799 & 0.059 & 1.267 & 1.365 & 1.933 \\
\hline \multirow{2}{*}{100} & $Q_{z}\left(\mathrm{~m}^{3} / \mathrm{min}\right)$ & 4.778 & 4.188 & 3.505 & 2.713 & 1.788 & 3.298 & 3.420 & 4.130 \\
\hline & $Q_{z}-Q_{t}\left(\mathrm{~m}^{3} / \mathrm{min}\right)$ & 3.407 & 2.747 & 2.134 & 1.342 & 0.417 & 1.919 & 2.049 & 2.759 \\
\hline
\end{tabular}

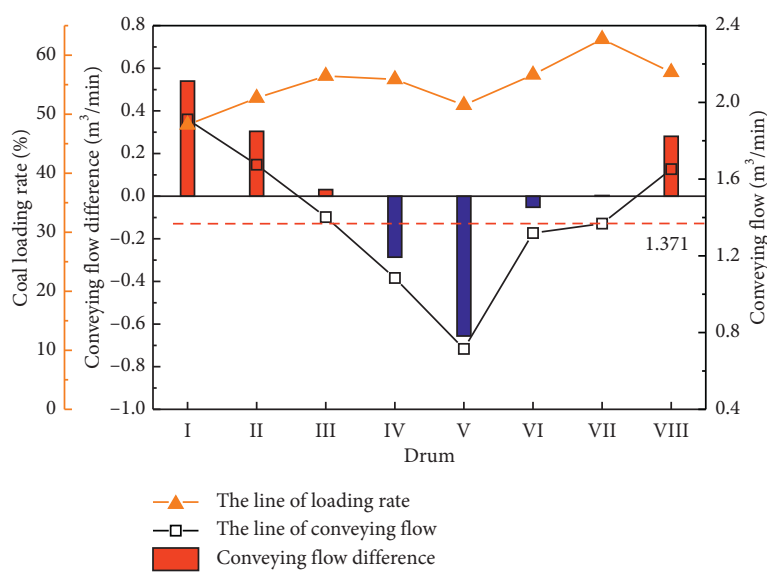

(a)

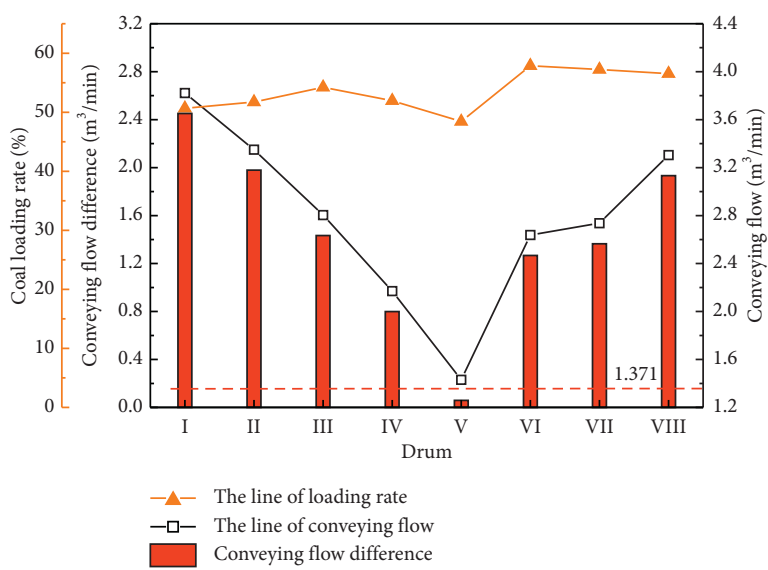

(c)

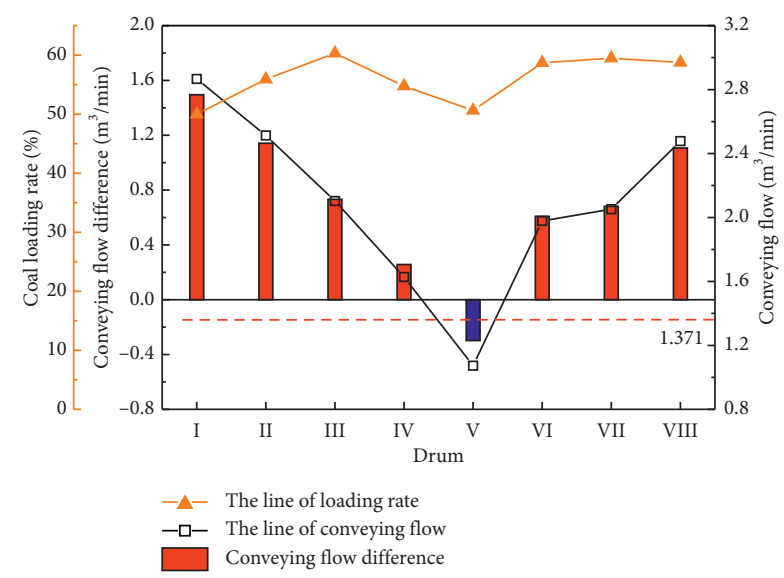

(b)

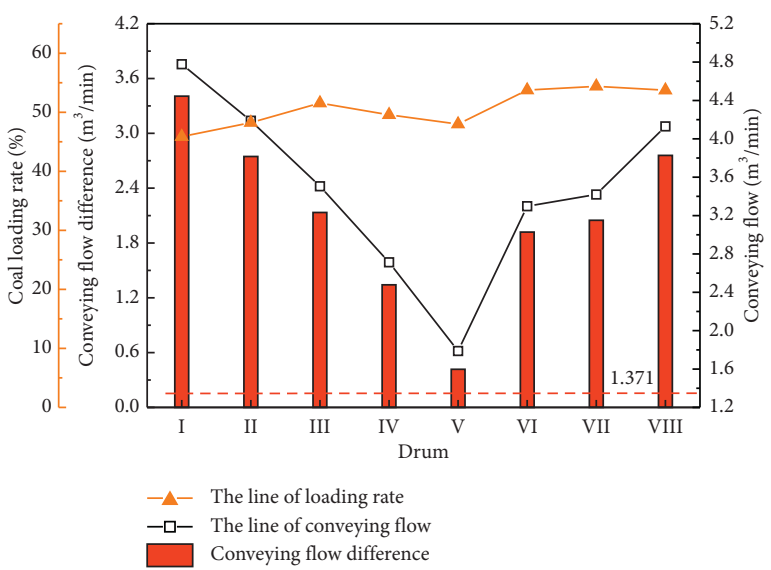

(d)

Figure 9: The relationship between the coal loading rate and coal conveying flow: (a) $40 \mathrm{rpm}$, (b) $60 \mathrm{rpm}$, (c) $80 \mathrm{rpm}$, and (d) $100 \mathrm{rpm}$.

As shown in Figures 12(f)-12(h), the change law of the coal loading rate of drum (VII) was consistent with the change law of particle cumulative mass, while the coal loading rate of drums (VI) and (VIII) increases first and then decreases as the rotational speed increases, which was not consistent with the change law of particle cumulative mass. The main reason was that the value of $K_{3}$ of drums (VI) and (VIII) was 0 , the structure of the drum hub was cylinder, while the structure of drum (VII) was still curve-shaped, which proved that the curve-shaped hub was more favorable to the axial movement of particles. Meanwhile, the coal loading rate of drum (VII) was generally higher than that of drums (VI) and (VIII), especially in the case of low rotational speed, which indicated that the hub with a small change of value of $K$ should be used in the conditions of low rotational speed.

By analyzing the relationship between coal loading rate and cumulative mass of particles in the conical hub drum and curve-shaped hub drum, respectively, it was found that the cumulative mass and the loading rate of the curve-shaped hub 


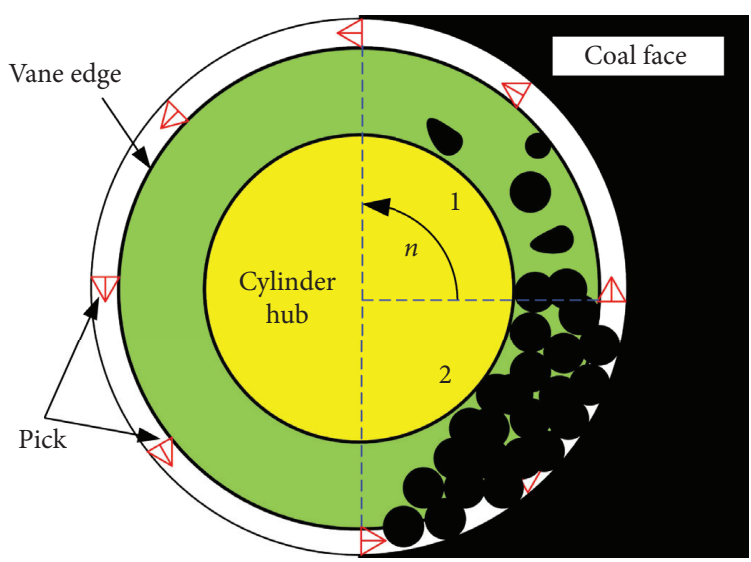

(a)

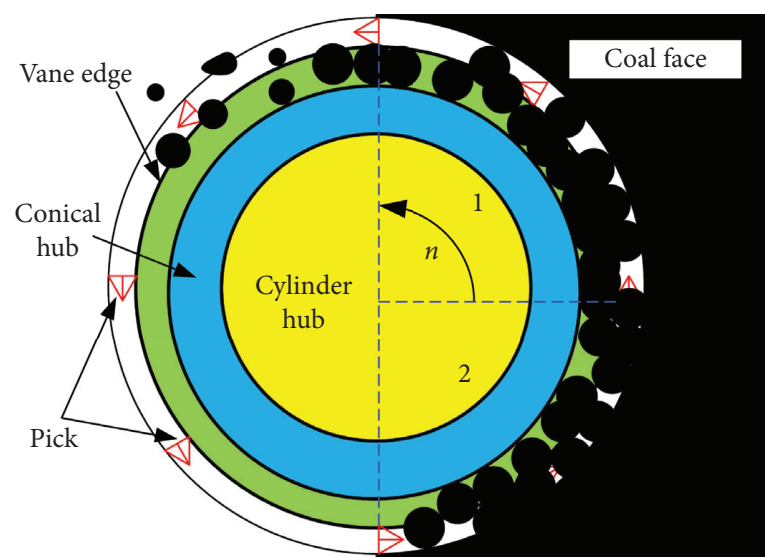

(b)

FIGURE 10: Schematic diagram of the influence of the drum space capacity on the coal conveying performance: (a) the coal conveying process with the cylinder hub drum; (b) the coal conveying process with the conical hub drum.

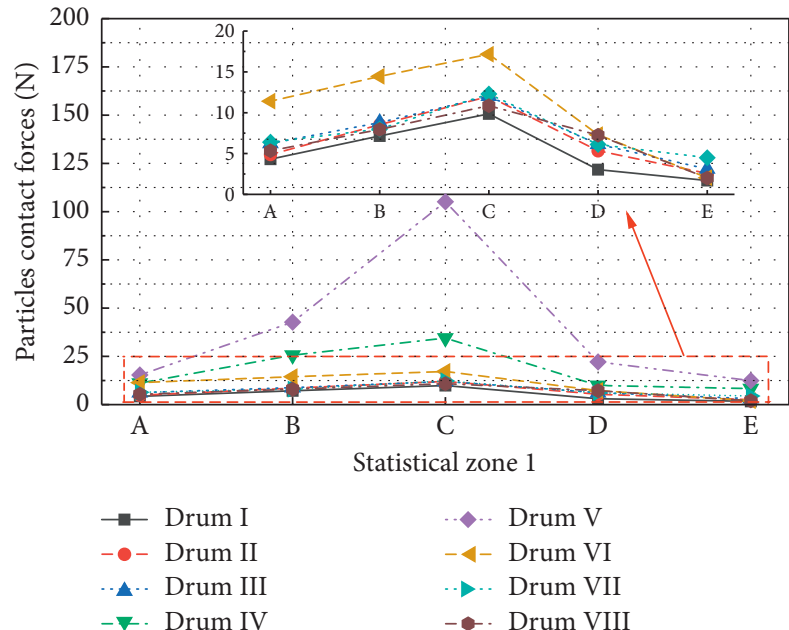

(a)

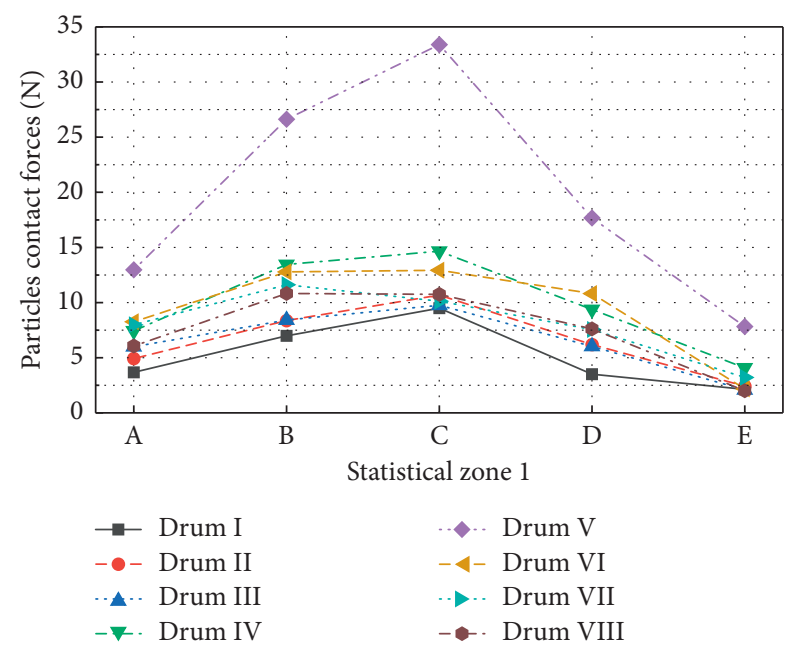

(c)

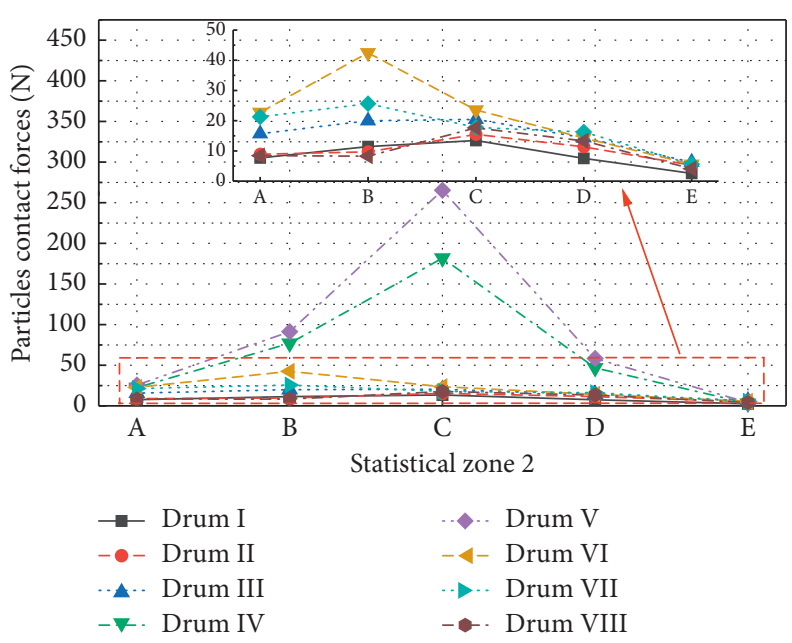

(b)

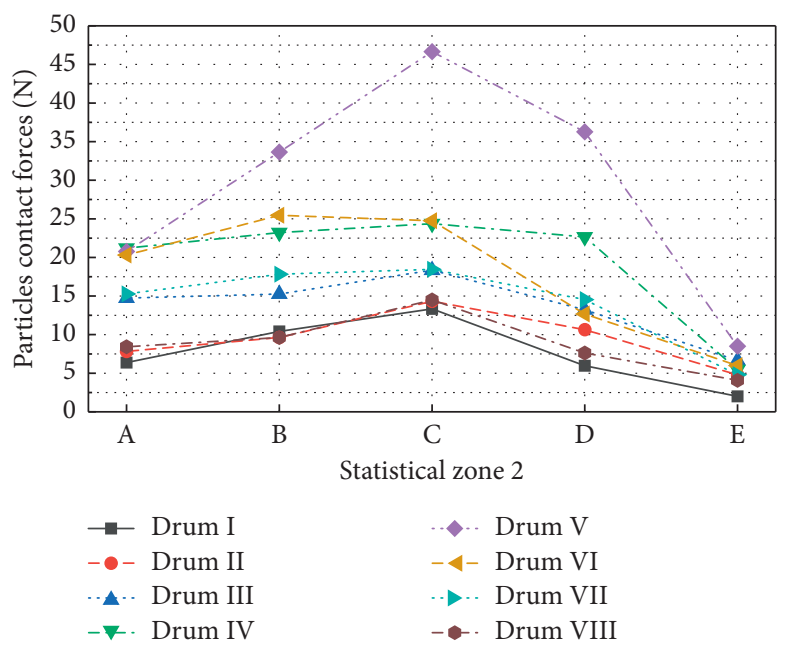

(d)

FIgURE 11: Continued. 

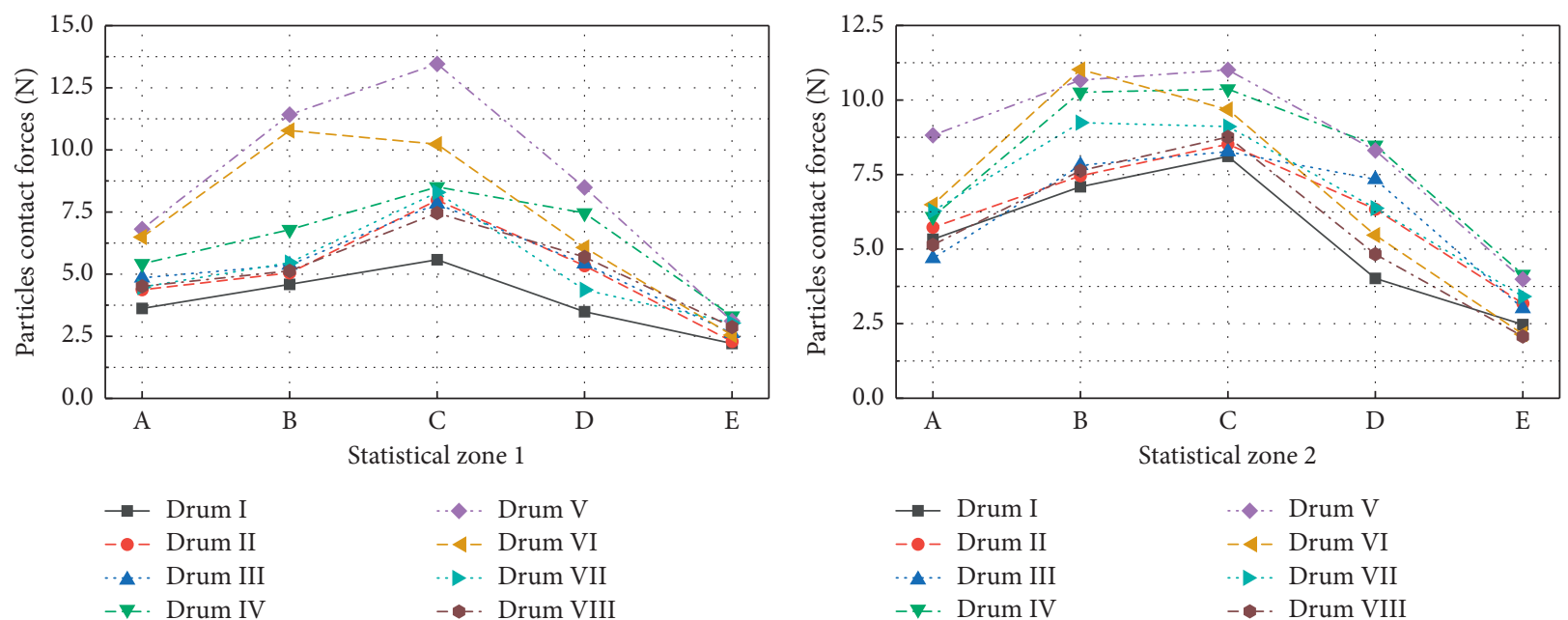

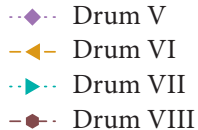

(e)

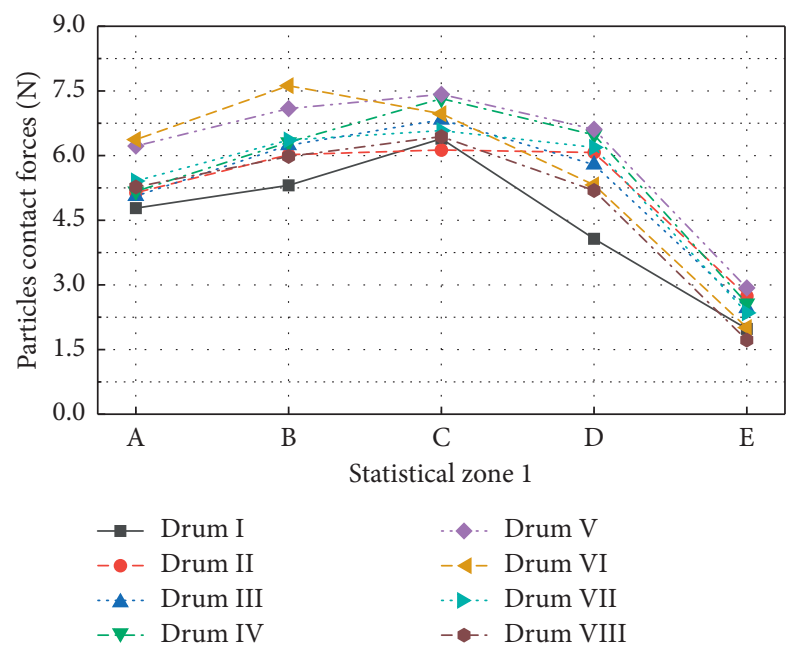

(g) (f)

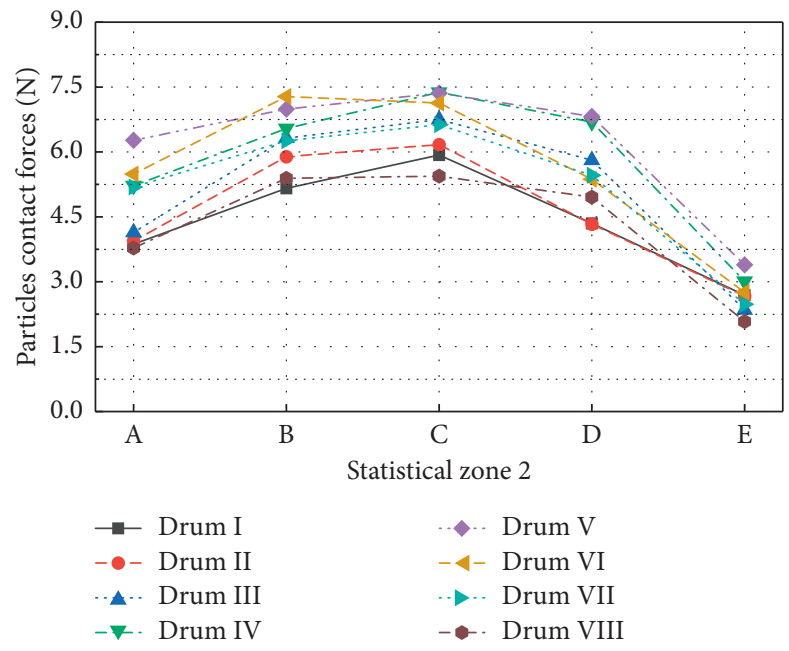

(h)

Figure 11: The contact force between particles in different statistical areas with different rotational speeds.

drum were both greater than those of the conical hub drum, which proved that the curve-shaped hub drum can provide a better drum space capacity and conveying performance.

Figure 13 shows the particle cumulative mass in different statistical areas of four drums ((I), (III), (V), and (VI)) changing with time. It can be seen from the figure that the particle cumulative mass in the area was linearly related to the time as the coal cutoff by the drum was a continuous process. Meanwhile, the particles move axially under the action of vanes through the statistical areas from zone A to E in turn. Therefore, in an ideal situation, the particle cumulative mass from zone $\mathrm{B}$ to $\mathrm{E}$ should be two to five times of that in zone A, respectively. In Figure 13, the slope of the fitting line of the particle cumulative mass should also increase linearly, correspondingly. While the actual situation was that, the difference of slope increases first and then decreases from zone A to E, as shown in Table 5. The main reason was that the movement of particles in the axial direction was fluent, and with the continuous accumulation of particles in the drum, more and more particles were thrown into the goaf, resulting in the decrease of slope difference. Additionally, due to the large drum space capacity of drum (I) and the large number of particles in the drum, the slope of the fitting line was larger than that of other drums. It can also be seen that compared with drums (I) and (III), the difference of the cumulative curve slope between statistical zones $\mathrm{A}$ and $\mathrm{B}$ and areas $\mathrm{B}$ and $\mathrm{C}$ in drum (I) was slightly bigger than that in drum (III), but the difference of the cumulative curve slope between statistical zones C and D and areas D and $\mathrm{E}$ in drum (I) was smaller than that in drum (III), which proved that the particle conveying performance of the cylinder hub was worse than that of the conical hub, which was consistent with the change law between the loading rate and particle cumulative mass. Due to the limitation of the drum space capacity, the slope difference of particle cumulative mass in different statistical areas of drums (V) and (VI) was smaller than that of the above two drums.

4.4. The Effect of the Drum Hub on the Loading Rate of Coal Particles in Different Web Depths. Figure 14 shows the 


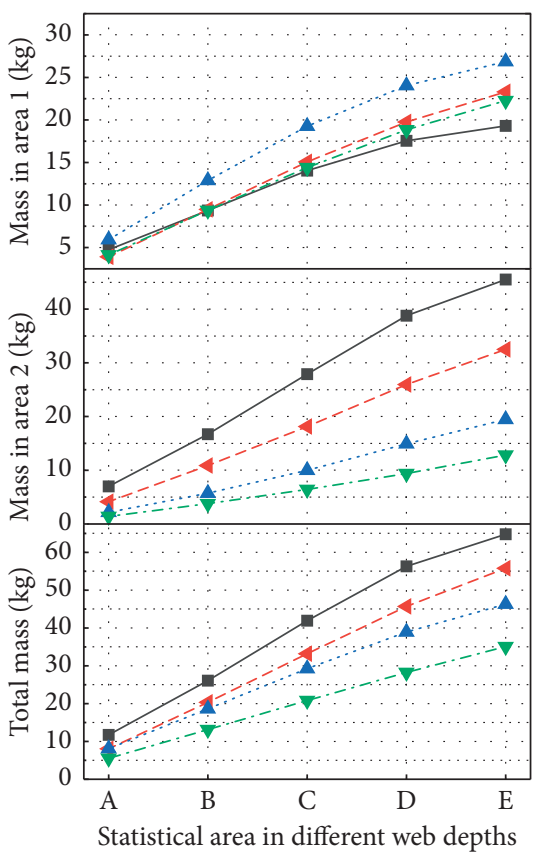

$$
\begin{array}{ll}
-40 \mathrm{rpm} & -180 \mathrm{rpm} \\
-4-60 \mathrm{rpm} & -\mathbf{*} .100 \mathrm{rpm}
\end{array}
$$

(a)

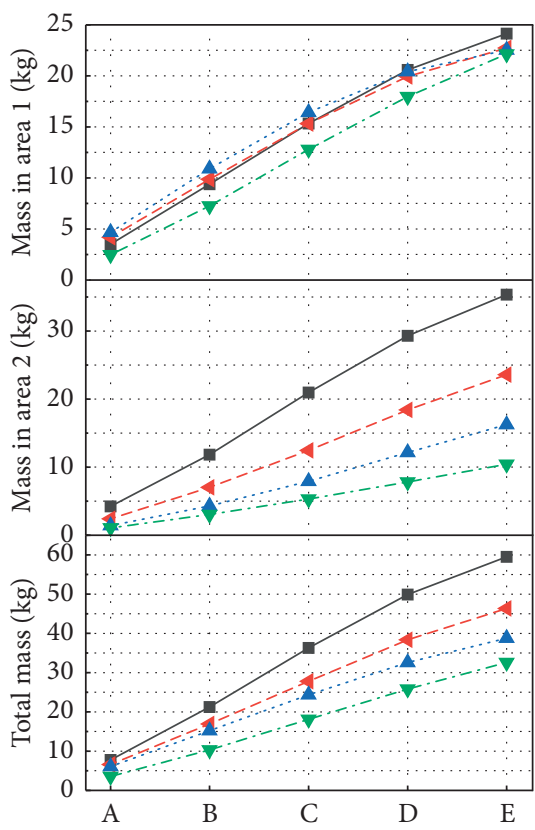

Statistical area in different web depths

$$
\begin{array}{ll}
\rightarrow-40 \mathrm{rpm} & \cdots \cdot . \\
-4-60 \mathrm{rpm} & -\cdots \cdot 100 \mathrm{rpm}
\end{array}
$$

(d)

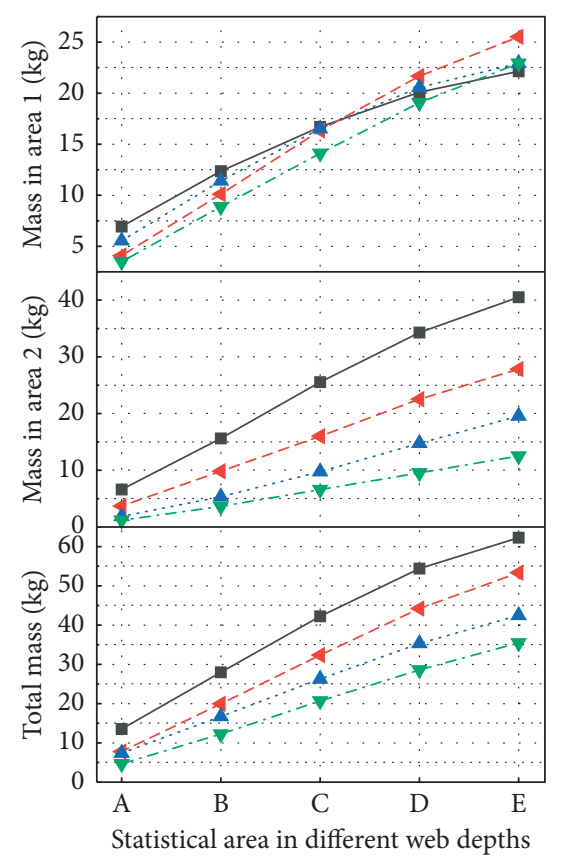

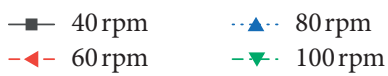

(b)

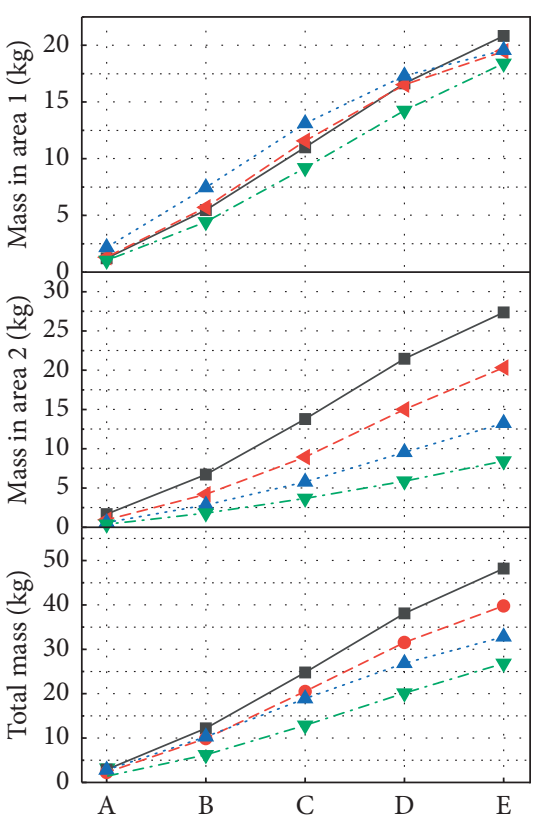

Statistical area in different web depths

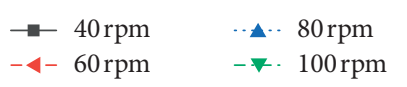

(e)

Figure 12: Continued.

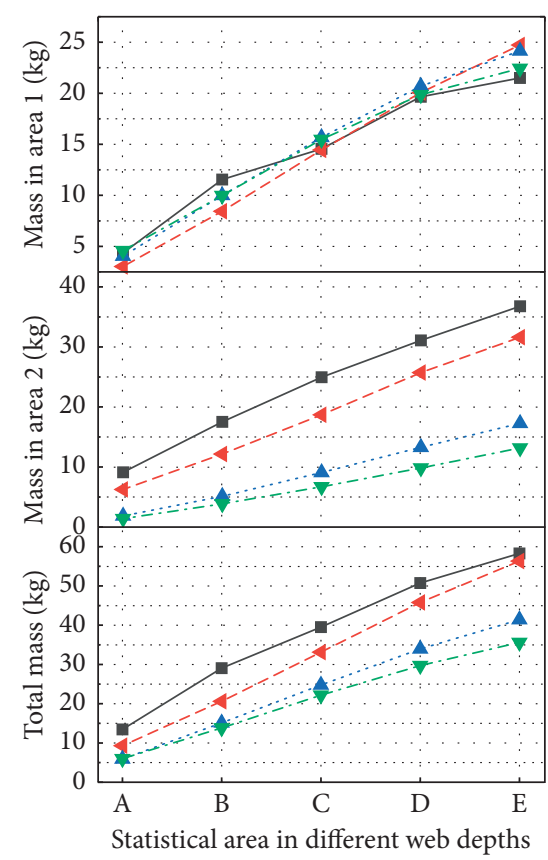

$\rightarrow 40 \mathrm{rpm} \quad$ - $-80 \mathrm{rpm}$

$-4-60 \mathrm{rpm} \quad-\rightarrow \cdot 100 \mathrm{rpm}$

(c)

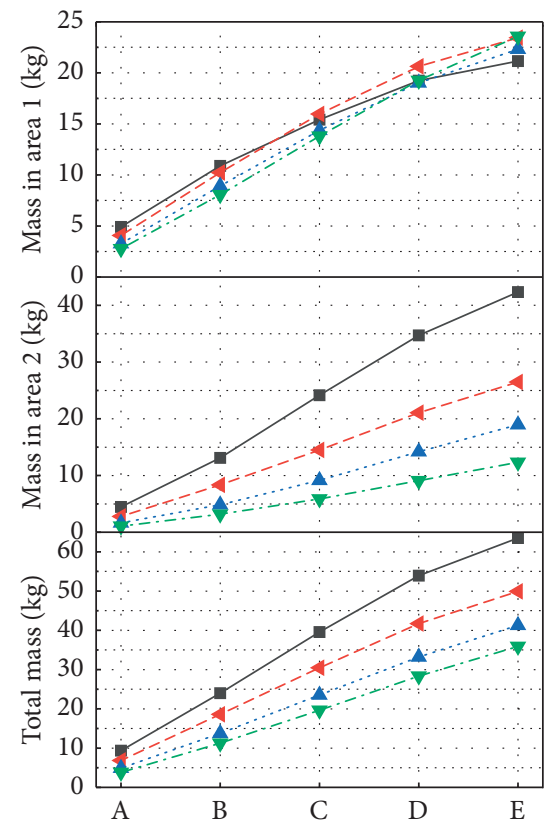

Statistical area in different web depths

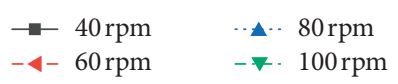

(f) 


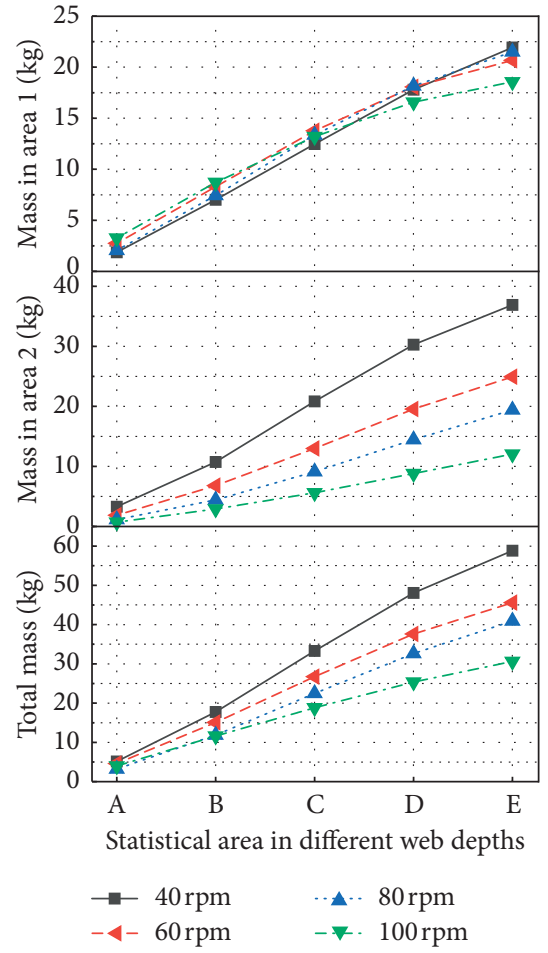

(g)

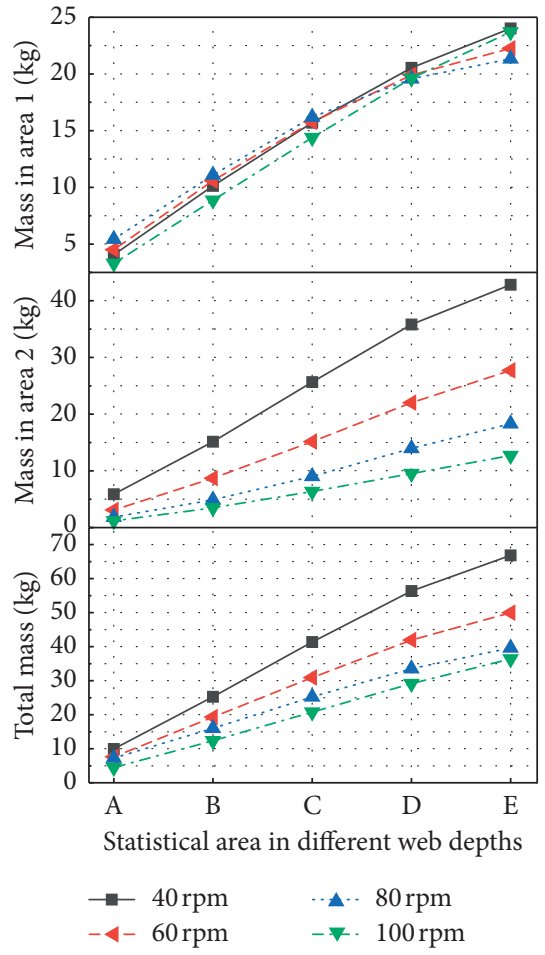

(h)

Figure 12: Cumulative mass of coal particles in different statistical areas: (a) drum I, (b) drum II, (c) drum III, (d) drum IV, (e) drum V, (f) drum VI, (g) drum VII, and (h) drum VIII.

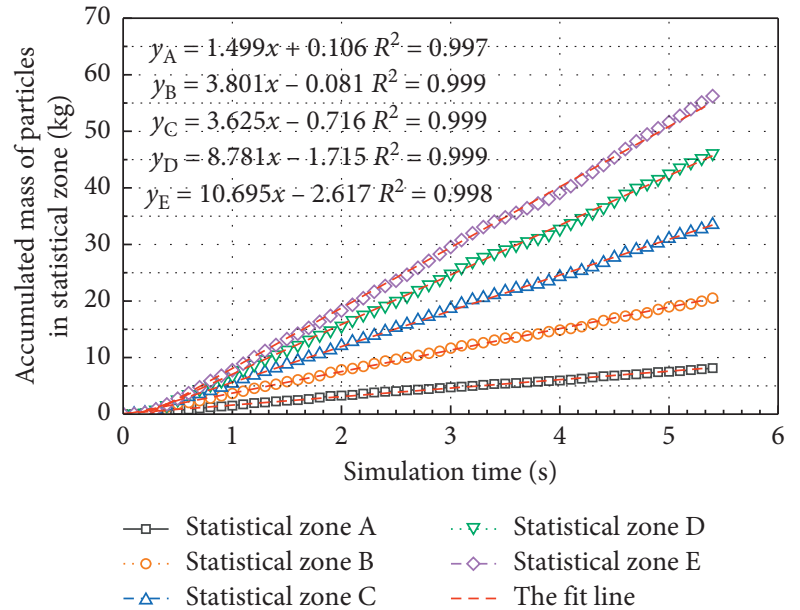

(a)

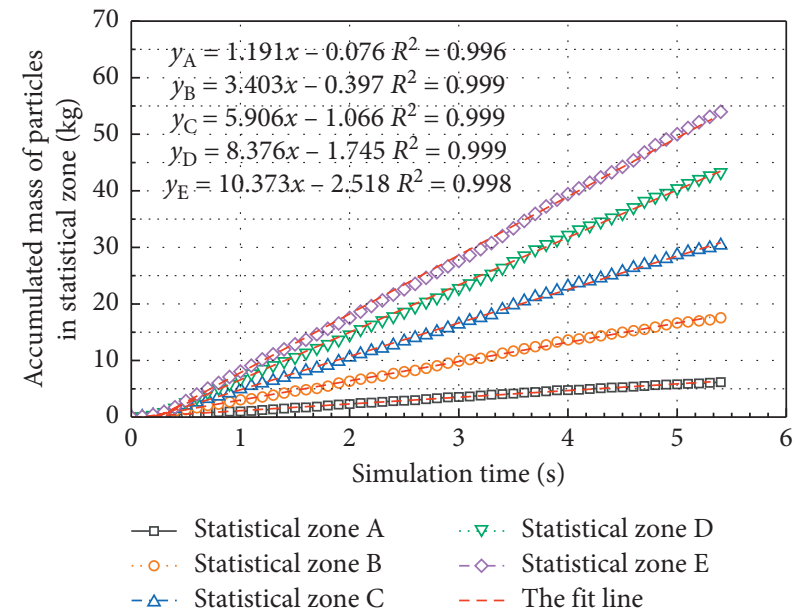

(b)

Figure 13: Continued. 


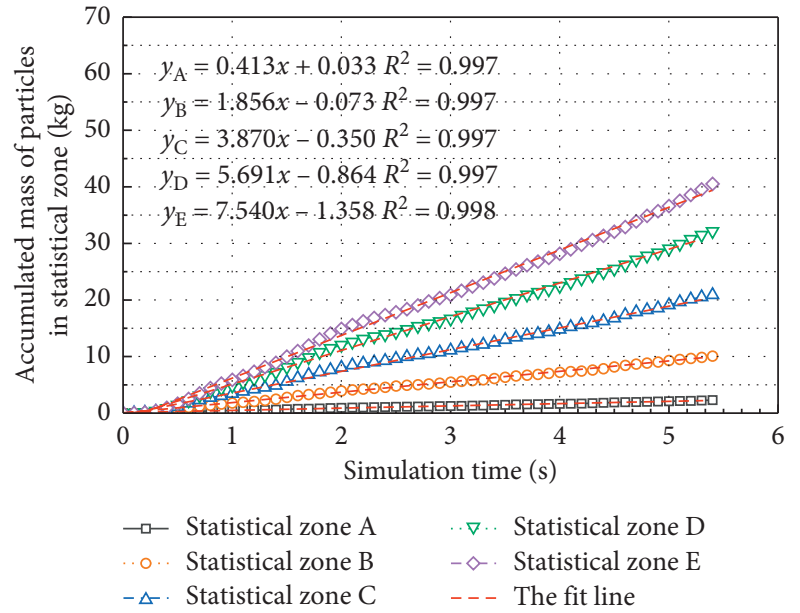

(c)

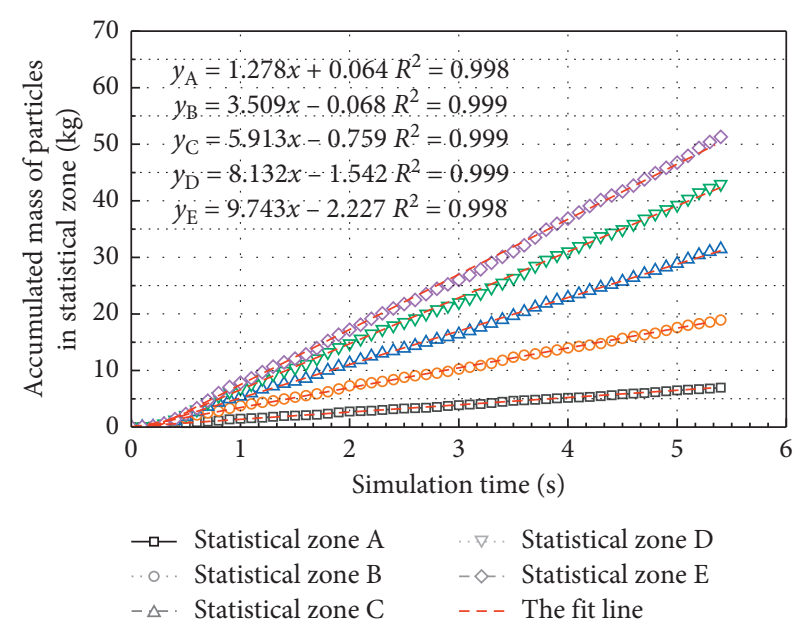

(d)

FIGURE 13: Cumulative mass of coal particles in different statistical areas changes with time at $60 \mathrm{rpm}$ : (a) drum I, (b) drum III, (c) drum V, and (d) drum VI.

TABLE 5: The difference of the slope of the cumulative coal particle mass curve in different statistical areas.

\begin{tabular}{|c|c|c|c|c|}
\hline \multirow[b]{2}{*}{ Drum } & \multicolumn{4}{|c|}{ The difference in the slope of the fitting line } \\
\hline & $y_{\mathrm{B}}-y_{\mathrm{A}}$ & $y_{\mathrm{C}}-y_{\mathrm{B}}$ & $y_{\mathrm{D}}-y_{\mathrm{C}}$ & $y_{\mathrm{E}}-y_{\mathrm{D}}$ \\
\hline I & 2.302 & 2.524 & 2.456 & 1.914 \\
\hline III & 2.212 & 2.503 & 2.470 & 1.997 \\
\hline $\mathrm{V}$ & 1.443 & 2.014 & 2.091 & 1.580 \\
\hline VI & 2.231 & 2.404 & 2.219 & 1.611 \\
\hline
\end{tabular}

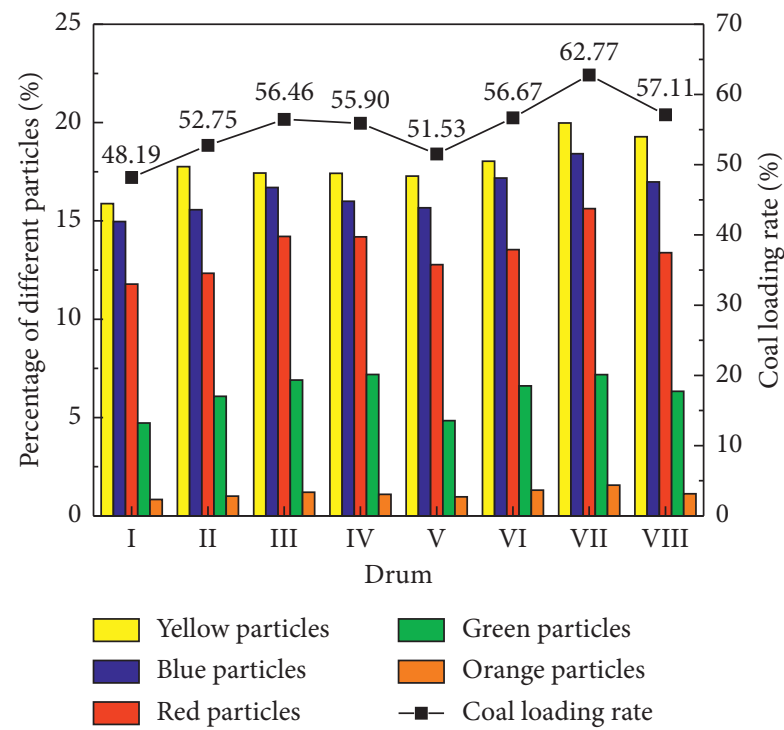

(a)

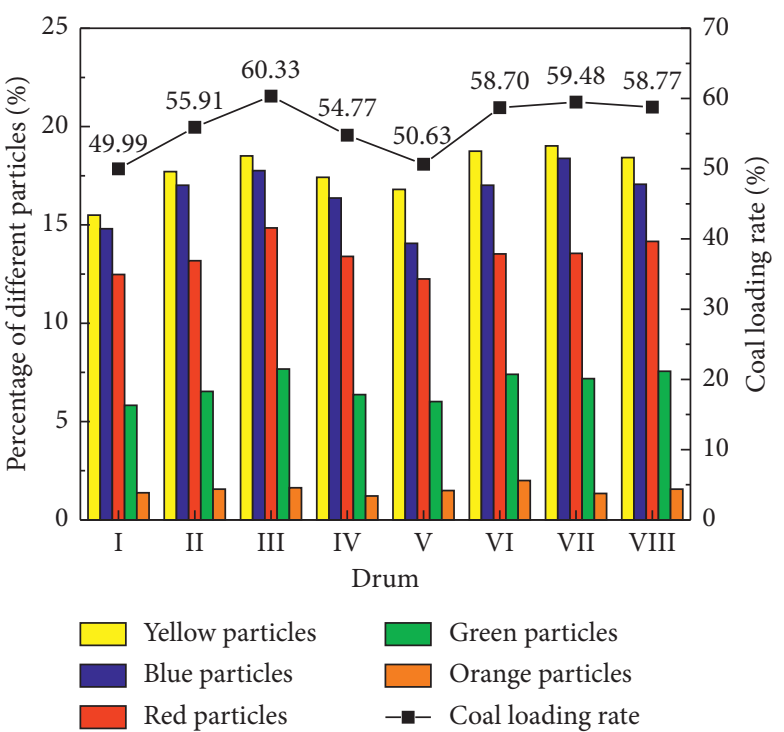

(b)

Figure 14: Continued. 


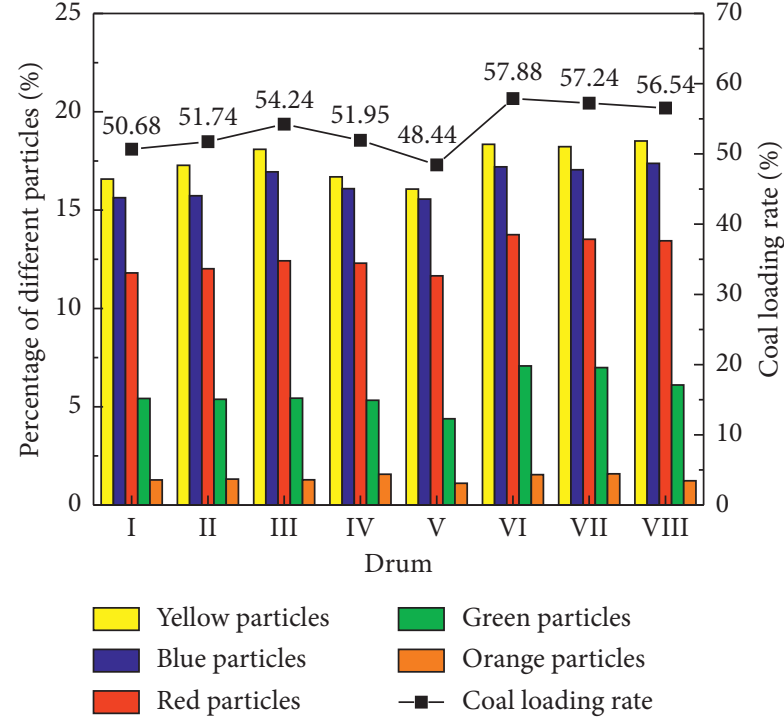

(c)

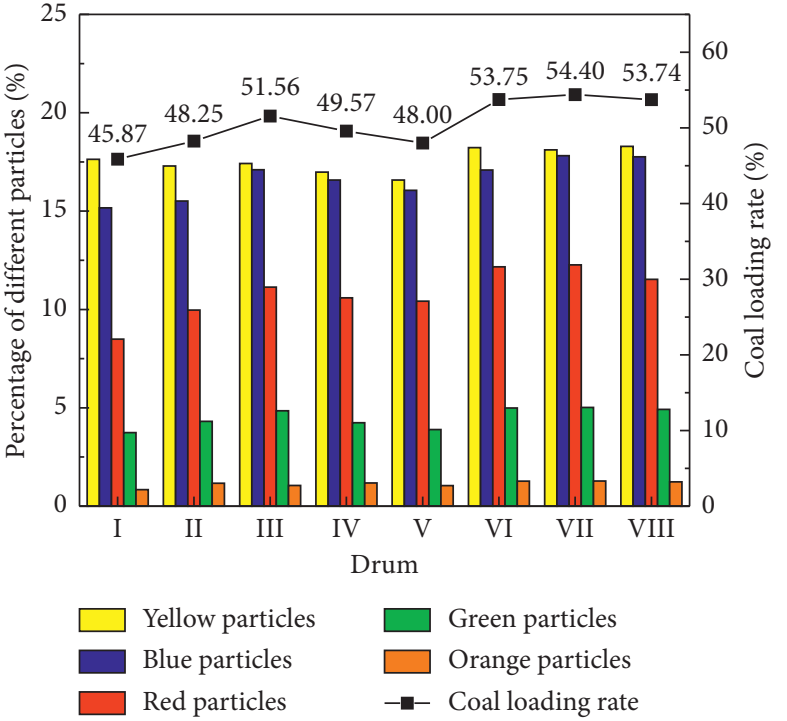

(d)

FiguRE 14: The relationship between the loading coal particles with different web depths at different rotational speeds and the coal loading rate of the drum: (a) $40 \mathrm{rpm}$, (b) $60 \mathrm{rpm}$, (c) $80 \mathrm{rpm}$, and (d) $100 \mathrm{rpm}$.

TABLe 6: The statistical results of coal particle mass in different areas.

\begin{tabular}{|c|c|c|c|c|c|c|}
\hline$n(\mathrm{rpm})$ & Drum & Area I $(\mathrm{kg})$ & Area II $(\mathrm{kg})$ & Area III $(\mathrm{kg})$ & Loading rate $(\%)$ & $E(\%)$ \\
\hline \multirow{8}{*}{40} & I & 41.80 & 21.64 & 59.02 & 48.19 & 17.67 \\
\hline & II & 37.62 & 20.24 & 64.60 & 52.75 & 16.53 \\
\hline & III & 35.49 & 17.82 & 69.15 & 56.46 & 14.55 \\
\hline & IV & 34.93 & 19.07 & 68.46 & 55.90 & 15.57 \\
\hline & $\mathrm{V}$ & 38.62 & 20.73 & 63.11 & 51.53 & 16.93 \\
\hline & VI & 35.27 & 17.78 & 69.41 & 56.67 & 14.52 \\
\hline & VII & 28.17 & 17.41 & 76.88 & 62.77 & 14.22 \\
\hline & VIII & 34.72 & 17.80 & 69.94 & 57.11 & 14.54 \\
\hline \multirow{8}{*}{60} & I & 42.22 & 19.02 & 61.22 & 49.99 & 15.53 \\
\hline & II & 35.83 & 18.16 & 68.47 & 55.91 & 14.83 \\
\hline & III & 32.30 & 16.27 & 73.89 & 60.33 & 13.29 \\
\hline & IV & 37.29 & 18.09 & 67.08 & 54.77 & 14.77 \\
\hline & $\mathrm{V}$ & 39.89 & 20.56 & 62.01 & 50.63 & 16.79 \\
\hline & VI & 33.82 & 16.75 & 71.89 & 58.70 & 13.68 \\
\hline & VII & 32.46 & 17.15 & 72.85 & 59.48 & 14.00 \\
\hline & VIII & 33.68 & 16.81 & 71.97 & 58.77 & 13.73 \\
\hline \multirow{8}{*}{80} & I & 43.78 & 16.61 & 62.07 & 50.68 & 13.56 \\
\hline & II & 43.67 & 15.42 & 63.37 & 51.74 & 12.59 \\
\hline & III & 40.14 & 15.89 & 66.43 & 54.24 & 12.98 \\
\hline & IV & 43.01 & 15.83 & 63.62 & 51.95 & 12.93 \\
\hline & $\mathrm{V}$ & 46.69 & 16.54 & 59.33 & 48.44 & 13.50 \\
\hline & VI & 36.54 & 15.03 & 70.89 & 57.88 & 12.27 \\
\hline & VII & 37.90 & 14.46 & 70.10 & 57.24 & 11.81 \\
\hline & VIII & 38.65 & 14.57 & 69.24 & 56.54 & 11.90 \\
\hline \multirow{8}{*}{100} & I & 55.50 & 10.79 & 56.17 & 45.87 & 8.81 \\
\hline & II & 49.34 & 14.03 & 59.09 & 48.25 & 11.46 \\
\hline & III & 47.01 & 12.30 & 63.15 & 51.56 & 10.04 \\
\hline & IV & 48.85 & 12.90 & 60.71 & 49.57 & 10.53 \\
\hline & V & 51.75 & 11.92 & 58.79 & 48.00 & 9.73 \\
\hline & VI & 43.57 & 13.06 & 65.83 & 53.75 & 10.66 \\
\hline & VII & 43.08 & 12.75 & 66.63 & 54.40 & 10.41 \\
\hline & VIII & 43.95 & 12.70 & 65.81 & 53.74 & 10.37 \\
\hline
\end{tabular}




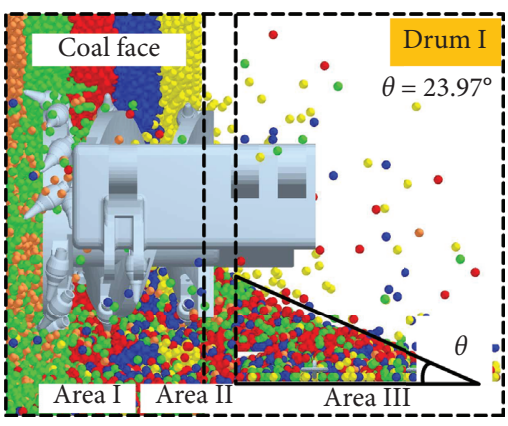

(a)

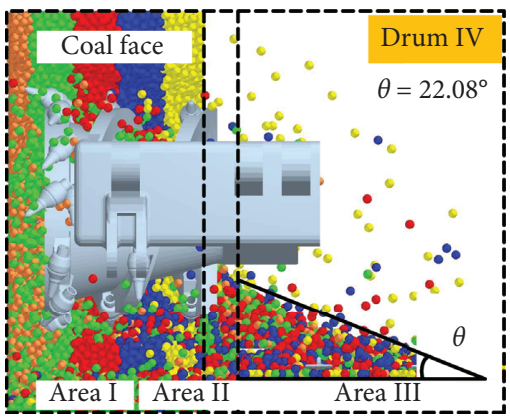

(d)

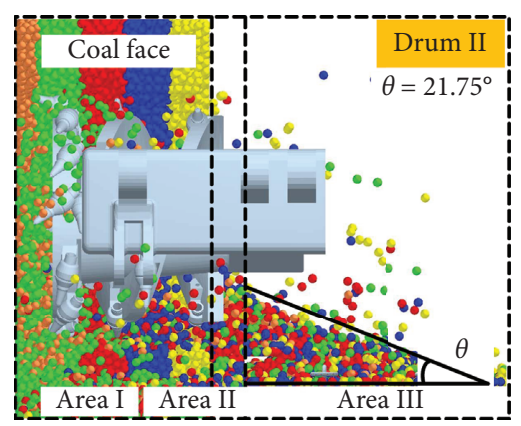

(b)

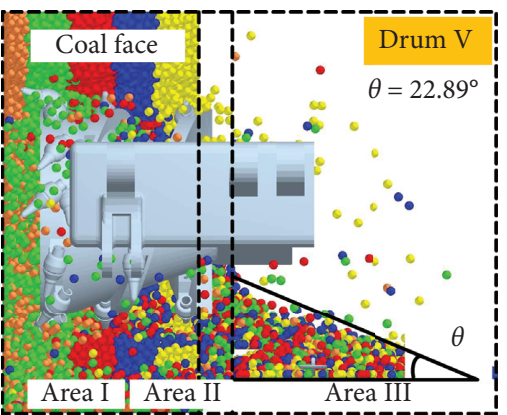

(e)

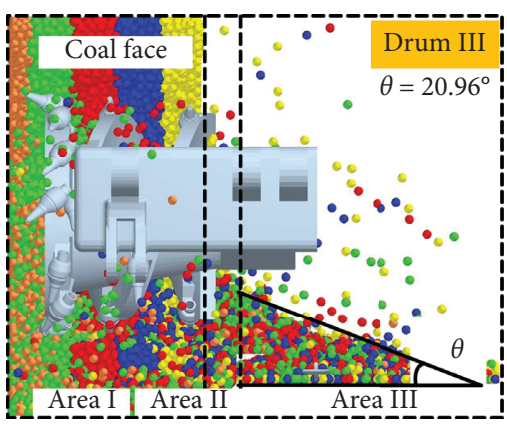

(c)

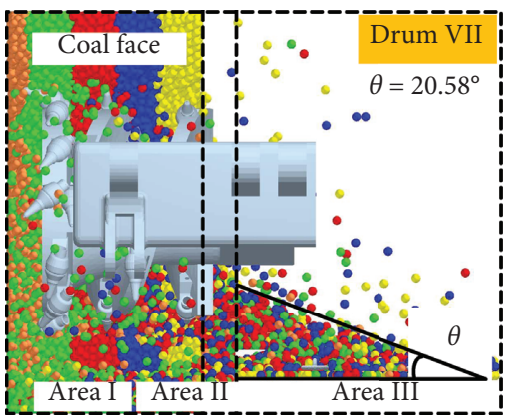

(f)

Figure 15: Simulation results in the DEM at rotational speed $40 \mathrm{rpm}$.

percentage of particles with different colors (representing different web depth positions) in the coal loading rate. As shown in the figure, the proportion of yellow particles in area III is the largest followed by blue, red, green, and orange particles, which was exactly the same with the web depth of particles with different colors. The proportion of yellow and red particles near the chain conveyor was relatively large, while that of orange and green particles was relatively small due to the larger web depth. Meanwhile, the change law of the drum loading rate was similar to the proportion trend of particles in colors of blue, red, and green, indicating that the coal particles in these colors mainly affected the coal loading performance of the drum. With the increase of rotating speed, the proportion of yellow and blue particles did not change significantly, while the proportion of red particles and green particles had a significant reduction, which proved that the particles near the chain conveyor were less affected by the drum rotating speed, and the high rotational speed had a negative impact on the conveying of particles with larger web depth.

Table 6 is the statistics of particle mass in each statistical area, where $E$ is the ratio of particle mass in statistical area II to the total mass of cutoff particles. It can be seen from the table that there was a negative correlation between the value of $E$ and the drum loading rate. Meanwhile, due to the influence of the particle axial velocity, the value of $E$ decreases with the increase in the value of $\psi$. When $\psi>100^{\circ}$, the value of $E$ increases with the increase in the value of $\psi$ due to the influence of the hub extrusion, which was especially obvious at a low rotational speed.

Figure 15 shows the loading process of the drum in the simulation when the rotational speed was $40 \mathrm{rpm}$. Under the action of vanes, the excavated particles were conveyed from the coal wall to the chain conveyor, and some of them were piled up in area II, which failed to load onto the conveyor. With the continuous mining, the particles were accumulated in area II, continuously, and the particles were stacked in the chute of the conveyor in a wedge shape. For the measurement of the stacking angle $\theta$ of particles, the value of $\theta$ was the angle between the bevel edge and the bottom edge. The larger the value of $\theta$ was, the more particles were piled up in area II, which will become an obstacle for the subsequent particles to be thrown out from the drum and affect the movement of the chain conveyor towards to the coal face. By analyzing Figure 14 and Table 6, the larger stacking angle was adverse on the drum loading performance.

\section{Conclusion}

Seven drums with different hub forms and structures were designed and developed based on the cylindrical hub drum. DEM was employed in this paper to study the loading performance of the drums above with different rotational speeds. The complex influence mechanism of the drum hub on the coal loading performance was analyzed and studied by some research objects, including the particle velocity, drum space capacity, and contact force between particles. The main conclusions are as follows:

(1) By analyzing the axial velocity variation of coal particles with different drum hubs from the simulation, it was found that the axial velocity of particles increases with the increase of hub cone angle; furthermore, the axial velocity difference on the lower 
rotational speed was obviously greater than that on the higher rotational speed. When the rotational speed of the drum increased from $40 \mathrm{rpm}$ to $100 \mathrm{rpm}$, the axial velocity difference of particles in the drum with a cone angle of $110^{\circ}$ and in the cylindrical hub drum decreased from 4 times to 2 times.

(2) The increased hub cone angle had a positive effect on increasing axial velocity of particles and the loading rate of particles at larger web depth; nevertheless, it had a negative effect on drum space capacity. The smaller drum space capacity would lead to drum choking and further lead to the bigger contact force between particles, overcrushing, and particle size reduction during the conveying process. Through the DEM simulation, the drum had a best coal loading performance with the cone angle $100^{\circ}$ and the rotational speed $60 \mathrm{rpm}$, and the coal loading rate was $60.33 \%$, which is about $10 \%$ higher than that of the cylindrical hub drum.

(3) Based on the conical hub drum, three drums with the curve-shaped hub were established. Compared with the conical hub drum, the curve-shaped hub drum not only increased the axial velocity of particles but also provided the bigger drum space capacity. Under the same rotational speed, the loading performance of the drum with the curve-shaped hub was better than that with the conical hub drum. Through the simulation, the best loading rate was obtained at $40 \mathrm{rpm}$ by the drum, whose curvature changed from $0.1224,0.07984$, and 0.02735 along the end plate to the discharge end, and the coal loading rate was $62.77 \%$.

\section{Data Availability}

The data used to support the findings of this study are included within the article.

\section{Conflicts of Interest}

The authors declare that they have no conflicts of interest.

\section{Acknowledgments}

This work was supported by the National Natural Science Foundation of China (51704178), the Natural Science Foundation of Shandong Province (ZR2017MEE034), the Open Foundation of Shandong Province Key Laboratory of Mine Mechanical Engineering (2019KLMM102), and the Project of Shandong Province Higher Educational Young Innovative Talent Introduction and Cultivation Team (Performance enhancement of deep coal mining equipment).

\section{References}

[1] O. Z. Hekimoglu and L. Ozdemir, "Effect of angle of wrap on cutting performance of drum shearers and continuous miners," Mining Technology, vol. 113, no. 2, pp. 118-122, 2004.
[2] B. Mishra, Analysis of Cutting Parameters and Heat Generation on Bits of a Continuous Miner-Using Numerical and Experimental Approach, College of Engineering and Mineral Resources at West Virginia University, Morgantown, WV, USA, 2007.

[3] D. Yang, J. Li, L. Wang, K. Gao, Y. Tang, and Y. Wang, "Experimental and theoretical design for decreasing wear in conical picks in rotation-drilling cutting process," The International Journal of Advanced Manufacturing Technology, vol. 77, no. 9-12, pp. 1571-1579, 2015.

[4] L. Zhao, H. Liu, and W. Zhou, "A study on the dynamic transmission law of spiral drum cutting coal rock based on ANSYS/LS-DYNA simulation," Complexity, vol. 2019, Article ID 1482051, 14 pages, 2019.

[5] S.-F. Liu, S.-F. Lu, Z.-J. Wan, H.-W. Zhang, and K.-K. Xing, "Numerical simulation of induced cutting in deep coal," Royal Society Open Science, vol. 6, no. 9, Article ID 190308, 2019.

[6] J. Huang, Y. Zhang, L. Zhu, and T. Wang, "Numerical simulation of rock cutting in deep mining conditions," International Journal of Rock Mechanics and Mining Sciences, vol. 84, pp. 80-86, 2016.

[7] C. M. Booker, "Theoretical and practical aspects of cutting and loading by shearer drums," Colliery Guardian, vol. 1, pp. 9-16, 1979.

[8] J. Ludlow and R. A. Jankowski, "Use low shearer drum speeds to achieve deeper coal cutting," Mining Engineering, vol. 36, pp. 251-255, 1984.

[9] S. S. Peng, Longwall Mining, United States, West Virginia University, Department of Mining Engineering, Morgantown, WV, USA, 2006.

[10] K. G. Hurt and F. G. Mcstravick, "High performance shearer drum design,” Colliery Guardian, vol. 236, pp. 425-429, 1988.

[11] M. Ayhan and E. M. Eyyuboglu, "Comparison of globoid and cylindrical shearer drums' loading performance," Journal of the South Africa Institute of Mining and Metallurgy, vol. 106, no. 1, pp. 55-56, 2006.

[12] S. Liu, C. Du, J. Zhang, and H. Jiang, "Parameters analysis of shearer drum loading performance," Mining Science and Technology (China), vol. 21, no. 5, pp. 621-624, 2011.

[13] K. Gao, C. Du, J. Dong, and Q. Zeng, "Influence of the drum position parameters and the ranging arm thickness on the coal loading performance," Minerals, vol. 5, no. 4, pp. 723-736, 2015.

[14] $€$. Bołoz, "Unique project of single-cutting head longwall shearer used for thin coal seams exploitation," Archives of Mining Sciences, vol. 58, no. 4, pp. 1057-1070, 2013.

[15] T. Wydro, "Influence of the plow filling and thread angle onto the plow head efficiency," Archives of Mining Sciences, vol. 60, no. 1, pp. 143-156, 2015.

[16] P. Gospodarczyk, "Modeling and simulation of coal loading by cutting drum in flat seams," Archives of Mining Sciences, vol. 61, no. 2, pp. 365-379, 2016.

[17] P. A. Cundall, "Computer model for simulating progressive large scale movements in blocky rock systems," in Proceedings of the Symposium of the International Society of Rock Mechanics, vol. 1, no. 2, Nancy, France, 1971.

[18] P. A. Cundall and O. D. L. Strack, "A discrete numerical model for granular assemblies," Géotechnique, vol. 29, no. 1, pp. 47-65, 1979.

[19] X. Deng, K. Zheng, and R. N. Davé, "Discrete element method based analysis of mixing and collision dynamics in adhesive mixing process," Chemical Engineering Science, vol. 190, pp. 220-231, 2018.

[20] C. Hang, Y. Huang, and R. Zhu, "Analysis of the movement behaviour of soil between subsoilers based on the discrete 
element method," Journal of Terramechanics, vol. 74, pp. 35-43, 2017.

[21] S. T. W. Karuneru, E. Sauret, S. C. Saha, and Y. T. Gu, "A coupled finite volume \& discrete element method to examine particulate foulant transport in metal foam heat exchangers," International Journal of Heat and Mass Transfer, vol. 115, pp. 43-61, 2017.

[22] S. Shrestha, S. B. Kuang, A. B. Yu, and Z. Y. Zhou, "Effect of van der Waals force on bubble dynamics in bubbling fluidized beds of ellipsoidal particles," Chemical Engineering Science, vol. 212, Article ID 115343, 2020.

[23] M. D. Sinnott and P. W. Cleary, "Particulate and water mixing in the feed box for a screen," Minerals Engineering, vol. 109, pp. 109-125, 2017.

[24] X. Wang, B. Li, S. Wang, Z. Yang, and L. Cai, "The transporting efficiency and mechanical behavior analysis of scraper conveyor," Proceedings of the Institution of Mechanical Engineers, Part C: Journal of Mechanical Engineering Science, vol. 232, no. 18, pp. 3315-3324, 2018.

[25] D. Ilic and C. A. Wheeler, "Transverse bulk solid behaviour during discharge from troughed belt conveyors," Advanced Powder Technology, vol. 28, no. 9, pp. 2410-2430, 2017.

[26] D. O. Potyondy and P. A. Cundall, "A bonded-particle model for rock," International Journal of Rock Mechanics and Mining Sciences, vol. 41, no. 8, pp. 1329-1364, 2004.

[27] Y. Dai, F. Ma, X. Zhu, H. Liu, Z. Huang, and Y. Xie, "Mechanical tests and numerical simulations for mining seafloor massive sulfides," Journal of Marine Science and Engineering, vol. 7, no. 8, p. 252, 2019.

[28] X. Li, S. Wang, S. Ge, R. Malekian, Z. Li, and Y. Li, "A study on drum cutting properties with full-scale experiments and numerical simulations," Measurement, vol. 114, pp. 25-36, 2018.

[29] K. D. Gao, "Feasibility of drum coal loading process simulation using three dimension discrete element method," Electronic Journal of Geotechnical Engineering, vol. 20, pp. 5999-6007, 2015.

[30] M. Ayhan, Investigation into the Cutting and Loading Performance of Drum Shearers in OAL Mine, The University of Hacettepe, Ankara, Turkey, 1994.

[31] K. D. Gao, X. Zhang, K. Jiang et al., "An applied model of minimum rotating speed for drum shearer to avoid drum clogging," Journal of Engineering, vol. 7, no. 1, pp. 1-19, 2019. 